\title{
Multi-season eddy covariance observations of energy, water and carbon fluxes over a suburban area in Swindon, UK
}

\author{
H. C. Ward $^{1,2}$, J. G. Evans ${ }^{1}$, and C. S. B. Grimmond ${ }^{2}$ \\ ${ }^{1}$ Centre for Ecology and Hydrology, Wallingford, Oxfordshire, UK \\ ${ }^{2}$ Department of Geography, King's College London, London, UK
}

Correspondence to: H. C. Ward (helrda@ceh.ac.uk)

Received: 9 October 2012 - Published in Atmos. Chem. Phys. Discuss.: 13 November 2012

Revised: 11 March 2013 - Accepted: 11 April 2013 - Published: 6 May 2013

\begin{abstract}
Eddy covariance measurements of the turbulent sensible heat, latent heat and carbon dioxide fluxes for 12 months (2011-2012) are reported for the first time for a suburban area in the UK. The results from Swindon are comparable to suburban studies of similar surface cover elsewhere but reveal large seasonal variability. Energy partitioning favours turbulent sensible heat during summer (midday Bowen ratio 1.4-1.6) and latent heat in winter (0.05-0.7). A significant proportion of energy is stored (and released) by the urban fabric and the estimated anthropogenic heat flux is small but non-negligible $\left(0.5-0.9 \mathrm{MJ} \mathrm{m}^{-2} \mathrm{day}^{-1}\right)$. The sensible heat flux is negative at night and for much of winter daytimes, reflecting the suburban nature of the site ( $44 \%$ vegetation) and relatively low built fraction $(16 \%)$. Latent heat fluxes appear to be water limited during a dry spring in both 2011 and 2012, when the response of the surface to moisture availability can be seen on a daily timescale. Energy and other factors are more relevant controls at other times; at night the wind speed is important. On average, surface conductance follows a smooth, asymmetrical diurnal course peaking at around $6-9 \mathrm{~mm} \mathrm{~s}^{-1}$, but values are larger and highly variable in wet conditions. The combination of natural (vegetative) and anthropogenic (emission) processes is most evident in the temporal variation of the carbon flux: significant photosynthetic uptake is seen during summer, whilst traffic and building emissions explain peak release in winter $\left(9.5 \mathrm{~g} \mathrm{C} \mathrm{m}^{-2} \mathrm{day}^{-1}\right)$. The area is a net source of $\mathrm{CO}_{2}$ annually. Analysis by wind direction highlights the role of urban vegetation in promoting evapotranspiration and offsetting $\mathrm{CO}_{2}$ emissions, especially when contrasted against peak traffic emissions from sectors with more roads. Given
\end{abstract}

the extent of suburban land use, these results have important implications for understanding urban energy, water and carbon dynamics.

\section{Introduction}

Understanding interactions between land surfaces and the atmosphere has an important role in assessing human impact on the environment and improving the predictive capability of models. Underpinning these models are representations of relevant processes governing the transport of heat, water, momentum and pollutants. Besides weather forecasting, simulations are increasingly used in the following ways: to predict the occurrence and impact of extreme events such as flooding or heat waves; to make informed planning decisions, such as identifying suitable sites for wind power generation (Heath et al., 2007) or assessing the effect of building form on pollutant dispersion (Xie et al., 2005; Balogun et al., 2010); and in the optimisation of strategies for sustainable water supplies (Mitchell et al., 2008) or thermal comfort (Lindberg and Grimmond, 2011). In order to develop and refine our understanding of such processes, observational datasets are required that encompass a range of environments and span sufficient timescales to offer insight into the driving factors.

That human behaviour impacts the environment has been well documented, particularly for urban areas where modification is most apparent. The construction of buildings, roads and other impervious surfaces, changes in vegetation cover and type and the behavioural patterns of people have been shown to dramatically affect local climatology, 
within the urban areas themselves and up to regional scales (Oke, 1987; Roth, 2000; Collier, 2006; Grimmond, 2010). Urban temperatures tend to be warmer than for the rural surroundings - the urban heat island effect (Oke, 1982; Arnfield, 2003). A higher proportion of sealed surfaces and reduced plant cover usually mean evaporation is lower in cities (Oke et al., 1999; Grimmond et al., 2004), whilst the amount of energy that can be stored in the thermal mass of buildings and anthropogenic materials becomes a major component of the energy balance (Grimmond and Oke, 1999b; Offerle et al., 2005a; Roberts et al., 2006). Direct input of heat released from human activities can also be significant, especially during winter months or in cool climates (Ichinose et al., 1999; Bergeron and Strachan, 2010) or in regions of very high population density (Hamilton et al., 2009). The energy balance for urban areas is thus modified from the rural case (Oke, 1987):

$Q^{*}+Q_{\mathrm{F}}=Q_{\mathrm{H}}+Q_{\mathrm{E}}+\Delta Q_{\mathrm{S}}$,

where $Q^{*}$ is the net all-wave radiation, $Q_{\mathrm{F}}$ the anthropogenic heat flux, $Q_{\mathrm{H}}$ the turbulent sensible heat flux, $Q_{\mathrm{E}}$ the latent heat flux and $\Delta Q_{\mathrm{S}}$ the net storage heat flux. In addition to anthropogenic heat, there are emissions of $\mathrm{CO}_{2}$ (and other gases) as a result of human metabolism and fuel combustion for transport or other energy use. High emission rates coupled with modification of the wind field by buildings and recirculation of trapped air within street canyons means air quality can be a major health risk in cities (Mayer, 1999). It is clearly vital to understand the impacts of urbanisation on the environment.

Suburban areas represent a significant, and increasing, proportion of the land surface worldwide. In the UK, urban areas cover $14.4 \%$ of the land surface (Home, 2009); most of this is made up of suburbs housing around $80 \%$ of the country's population (Gwilliam et al., 1998). The results presented here are the first suburban measurements of energy, water and carbon fluxes in the UK. Previous urban flux campaigns in the UK have taken place in city centres, with work in central London (Helfter et al., 2011; Kotthaus and Grimmond, 2012) and Edinburgh (Nemitz et al., 2002). Annual total emissions of $\mathrm{CO}_{2}$ for both London and Edinburgh are around $10 \mathrm{~kg} \mathrm{C} \mathrm{m}^{-2} \mathrm{yr}^{-1}$, considerably larger than the emissions from other studied cities around the world (Helfter et al., 2011; Järvi et al., 2012).

Other highly urbanised city campaigns (of various durations) have included Mexico City (Oke et al., 1999), Marseille (Grimmond et al., 2004), Tokyo (Moriwaki and Kanda, 2004) and Łódź (Offerle et al., 2005a). Energy balance measurements over lower density sites include the following: winter to spring in Vancouver (Grimmond, 1992); winter to autumn (9 months) in Helsinki (Vesala et al., 2008); the dry season in Ouagadougou (Offerle et al., 2005b); and summertime in Miami (Newton et al., 2007), Tucson, Sacramento, Chicago and Los Angeles (Grimmond and Oke, 1995). The least built-up sites documented in the urban literature include a highly vegetated neighbourhood in Baltimore (Crawford et al., 2011) and a recently developed low-density residential area in Kansas City (Balogun et al., 2009). Despite the increase in field studies in recent years, there is still demand for multi-seasonal flux datasets covering the diverse range of urban landscapes (Grimmond et al., 2010).

There are a few comparisons between multiple areas within the same city. As part of the BUBBLE project, three rural, three urban and one suburban site in Basel, Switzerland, were monitored simultaneously for 1 month in the summer of 2002 (Christen and Vogt, 2004). Offerle et al. (2006) present data from rural, suburban residential, dense urban and industrial areas in Łódź. Four sites of increasing housing density are compared in Melbourne (Coutts et al., 2007b). Weber and Kordowski (2010) compare $1 \mathrm{yr}$ of data for urban residential and suburban (residential bordering parkland) zones in Essen, Germany, and three sites along a rural-urban transect are contrasted during winter in Montreal (Bergeron and Strachan, 2010).

The objective of this paper is to investigate the temporal variability of energy, water and carbon exchange of a typical suburban area within the UK (Sect. 2) using local-scale $\left(10^{2}-10^{4} \mathrm{~m}\right)$ eddy covariance (EC) measurements (Sect. 3). Attention is given to the representativeness of the 12-month study period (Sect. 4) and the role of variability in surface cover on flux measurements (Sect. 5.4). Temporal changes in the observed fluxes are examined and related to the physical processes which govern surface-atmosphere exchange (Sect. 5). In particular, the influences of water availability, vegetation and anthropogenic activities are considered. Estimation of the surface conductances under different conditions offers empirical data for comparison with models or model development (Sect. 5.2).

\section{Site description}

The study was conducted within the town of Swindon, $120 \mathrm{~km}$ west of London (Fig. 1), in a residential area very typical of UK suburbia. Swindon has a population of 175000 and in recent years has been one of the fastest growing towns in Europe. High population density in southern England puts pressure on water supplies and creates demand for land to build on: it is estimated that $10 \%$ of new homes built in the UK in 2007 are situated in areas at risk of flooding (Home, 2009). Swindon has previously experienced problems with both flooding and drought.

An eddy covariance mast was installed in a residential garden located approximately $3 \mathrm{~km}$ north of Swindon town centre $\left(51^{\circ} 35^{\prime} 4.6^{\prime \prime} \mathrm{N}, 1^{\circ} 47^{\prime} 53.2^{\prime \prime} \mathrm{W}\right)$. The area has some institutional buildings (schools) and light commercial buildings (small supermarkets, local shops) along the main road that runs about $150 \mathrm{~m}$ south of the mast (Fig. 1). Southwest of the mast is the area with the largest proportion of built 

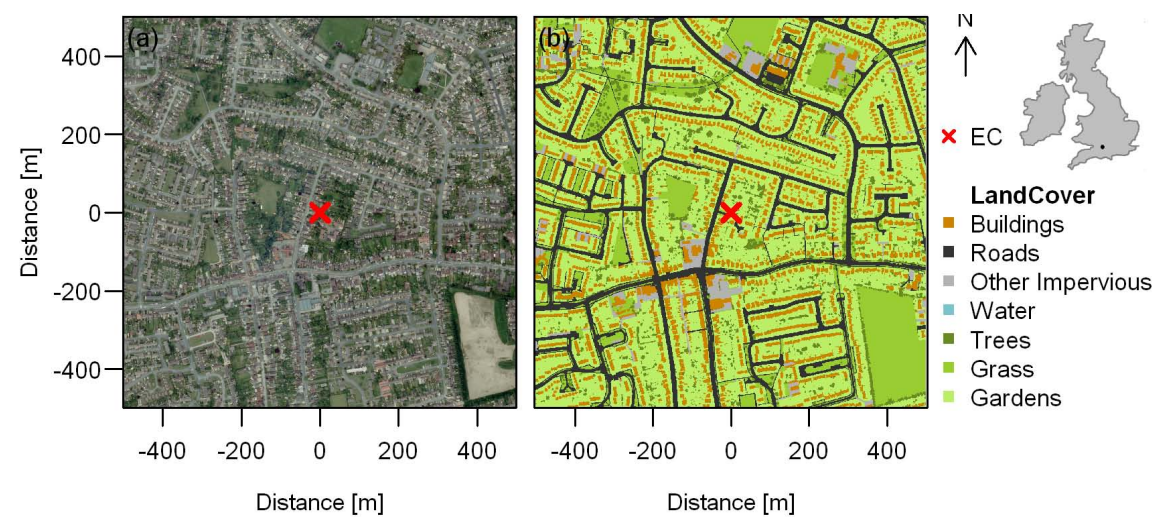

Fig. 1. (a) Aerial photograph $\left(2009,{ }^{\odot}\right.$ GeoPerspectives) and (b) land cover map for $\pm 500 \mathrm{~m}$ around the flux mast (EC). The large area southeast of the mast classified as grass in (b) has since been built on (it can be seen undergoing development in (a)). The location of Swindon within the British Isles is shown (top right).

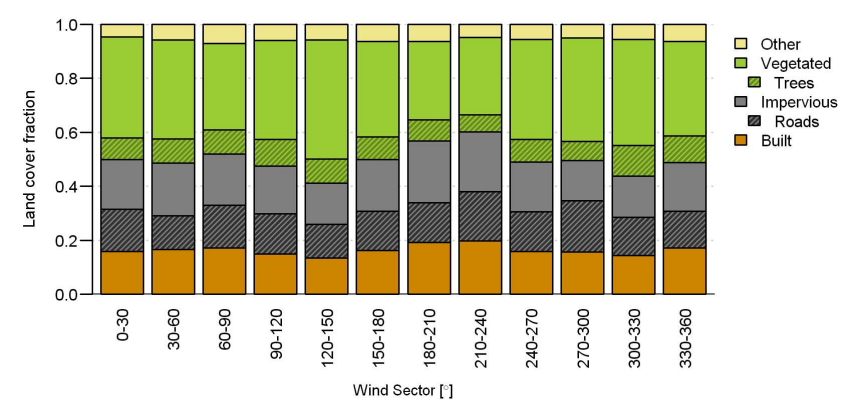

Fig. 2. Land cover fractions for $30^{\circ}$ wind sectors within a radius of $500 \mathrm{~m}$ around the flux mast.

and impervious surface cover and least vegetation (Fig. 2). However, the study area as a whole has significant vegetation cover (vegetated plan area fraction, $\lambda_{V}=0.44$ within a $500 \mathrm{~m}$ radius of the mast, Table 1), comprising mainly gardens, some open space (playing fields, parks, intentionally undeveloped green corridors) and verges alongside roads. A large nature reserve lies $0.75-1 \mathrm{~km}$ to the northeast.

The trees and shrub - which constitute $9 \%$ of the total area (500 $\mathrm{m}$ radius) - are within gardens, bordering open green spaces, in green corridors and along roadsides (Fig. 1). The average tree height is around $6 \mathrm{~m}$ (defining trees as vegetation $>3.5 \mathrm{~m}$ ). Species are predominantly deciduous rather than evergreen. The tree canopy is very apparent when looking across the study area and changes in leaf area dominate seasonal variation in the appearance of the landscape. Directly northeast of the mast the properties have relatively large gardens with a large proportion of mature trees (Fig. 1).

Buildings are mostly 1-2 storeys, with more single storey housing to the north of the mast and a few three storey blocks of flats to the south. The population density is around 4700
Table 1. Land cover within a radius of $500 \mathrm{~m}$ around the flux mast. Land cover not classified by these classes comprised less than $0.5 \%$ of the total area. "Trees" includes all vegetation not classified as grass (i.e. includes hedges, shrubs, small bushes).

\begin{tabular}{lc}
\hline Land cover type & Area fraction \\
\hline Buildings & 0.16 \\
Impervious & 0.33 \\
$\quad$ - roads & 0.15 \\
$\quad$ - within gardens & 0.15 \\
Vegetation & 0.44 \\
$\quad$ - grass & \multicolumn{2}{c}{0.36} \\
$\quad$ trees & 0.09 \\
Water & 0.00 \\
Pervious (bare soil, gravel) & 0.06 \\
\hline
\end{tabular}

inh $\mathrm{km}^{-2}$ in this area of Swindon ${ }^{1}$. The average building height is $4.5 \mathrm{~m}$ and the proportion of built area, $\lambda_{\mathrm{B}}$, is 0.16 . The style, density and arrangement of housing vary between neighbourhoods (Fig. 1) but are typical of today's UK suburban areas. Many houses are packed into the available space with compact new-build homes constructed between older developments. Most houses have small gardens which usually include some paved (or otherwise) impervious area (patios, driveways). The total impervious land cover fraction, $\lambda_{\mathrm{I}}$, is 0.33 , with almost half attributable each to roads and impervious surfaces within gardens (Table 1).

From the mean obstacle height, the displacement height, $z_{\mathrm{d}}$, is estimated to be $3.5 \mathrm{~m}$ and the roughness length for momentum, $z_{0}$, to be $0.5 \mathrm{~m}$. Using $z_{\mathrm{d}}=3.5 \mathrm{~m}$, anemometrically derived $z_{0}$ ranges between $0.25 \mathrm{~m}$ and $2.00 \mathrm{~m}$ for different wind directions, with the larger values attributed to the effect of nearby buildings. Similar variability has been observed at other sites (Grimmond et al., 1998; Pawlak et al., 2010; Nordbo et al., 2013) and $z_{\mathrm{d}}$ will also vary to some extent. The

\footnotetext{
${ }^{1}$ http://www.ons.gov.uk
} 
literature suggests a realistic range of $z_{0}$ for this site may be about $0.3-1.0 \mathrm{~m}$ (Grimmond and Oke, 1999a). The value of $0.5 \mathrm{~m}$ is adopted here.

The footprint model of Hsieh et al. (2000) was used to determine the probable source area of the turbulent fluxes. During stable conditions the measurement footprint can extend over many hundreds of metres; under unstable conditions it is much closer to the mast. For the majority $(89 \%)$ of the data $(\zeta<0.1$, i.e. unstable to just-stable conditions) the peak contribution to the measured flux is predicted to come from within $100 \mathrm{~m}$ of the mast and $80 \%$ of the source area lies within $700 \mathrm{~m}$ (using $z_{0}=0.5 \mathrm{~m}$ and $z_{\mathrm{d}}=3.5 \mathrm{~m}$ ). Although the land cover fractions will vary for different flux footprints, even within the same wind sector, there are clear differences between the higher vegetation fraction (to the northeast) and more built-up areas (to the southwest).

The land cover classification was based mainly on a geodatabase (OS MasterMap $2010{ }^{\circ}$ Crown Copyright), with a spatial resolution of $1 \mathrm{~m}$, in combination with lidar data $\left({ }^{\odot}\right.$ Infoterra Ltd, 2007) and aerial photography ( ${ }^{\circ}$ GeoPerspectives, 2009). To determine the locations of trees not specifically classified by the database, vegetated areas with an obstacle height greater than $3.5 \mathrm{~m}$ were defined as trees. For the wind sector $120-150^{\circ}$ a large proportion of vegetation is shown in Fig. 2, which is partly attributable to the corner of the large grassed area in this sector (Fig. 1b) that has since been built on (under development in Fig. 1a). Hence, the land cover fractions for $120-150^{\circ}$ are least representative of the current land cover and overestimate the contribution from vegetation. Aside from this change, the classification scheme and aerial photograph are judged to be good representations of the surface cover during the measurement period (based on observations when visiting the site). To establish the composition of gardens (classified only as multiple surfaces by the database), 96 randomly selected gardens were subdivided into different surface cover types by visual inspection of aerial photography. Then the average surface cover percentages obtained were used to apportion the area of "garden" into grass, trees, paved, bare soil, etc. Although significant variation was seen between gardens, the sample was judged to be sufficiently large for clear trends to emerge (running means approached constant values) and consistent results were obtained for the identification of trees using lidar data.

\section{Instrumental setup, data collection and data processing}

Eddy covariance measurements were made on a pneumatic mast at $12.5 \mathrm{~m}$ above ground level (108 $\mathrm{m}$ above sea level), providing a measurement height, $z_{\mathrm{m}}$, of 2-3 times the height of the roughness elements. Fast-response temperature and wind measurements from a sonic anemometer (R3, Gill
Instruments, Lymington, UK) combined with water vapour and carbon dioxide from an open-path infrared gas analyser (IRGA) (LI-7500, LI-COR Biosciences, Lincoln, USA) yield turbulent sensible and latent heat fluxes and the carbon flux $\left(F_{\mathrm{C}}\right)$. On the same mast a four-component radiometer (NR01, Hukseflux Thermal Sensors, Delft, the Netherlands), at a height of $10.1 \mathrm{~m}$, provides incoming and outgoing longwave ( $L_{\downarrow}$ and $\left.L_{\uparrow}\right)$ and shortwave $\left(K_{\downarrow}\right.$ and $\left.K_{\uparrow}\right)$ radiation and net all-wave radiation. Additional meteorological data are supplied by an automatic weather station (WXT510, Vaisala, Finland) at $10.6 \mathrm{~m}$, also on the same mast. The field of view of the downward-facing radiation sensors encompasses a range of surfaces: gardens, roads, pavements, grass verges, hedges and small trees, bare soil, gravel, roofs of garages, small sheds and single-storey extensions, and brick and painted walls. Following Schmid et al. (1991), 95\% of the radiometer source area is calculated to lie within a radius of $44 \mathrm{~m}$ from the mast. At the same site, there is a tipping bucket rain gauge $(0.2 \mathrm{~mm}$ tip, Casella CEL, Bedford, UK) and a digital camera (CC5MPX, Campbell Scientific Ltd, Loughborough, UK) which provides a visual indication of conditions within the garden (changing phenology, snow cover). Soil moisture (CS616, Campbell Scientific Ltd) and soil temperature (model 107, Campbell Scientific Ltd) sensors were installed around the base of the mast, measuring different surfaces within the garden. Soils are mainly clayey loams with some sandier areas. A wetness sensor (model 237, Campbell Scientific Ltd) positioned in a nearby flowerbed provides an indication of whether the surface is wet or dry. Soil heat flux plates (HFP01, Hukseflux) were installed within the garden; data used here $\left(Q_{\mathrm{G}}\right)$ are from sandy soil at a depth of $0.03 \mathrm{~m}$. No adjustment was made for heat storage in the soil layer above the plate.

The raw flux data were logged at $20 \mathrm{~Hz}$ (CR3000, Campbell Scientific Ltd) and post-processed to $30 \mathrm{~min}$ statistics. Meteorological data are available at a resolution of $1 \mathrm{~min}$ (CR1000, Campbell Scientific Ltd), although $30 \mathrm{~min}$ block averages are presented here to match the eddy covariance output. Data transfer via a wireless router (Sierra Raven XE, Sierra Wireless, USA) enables daily collection and real-time monitoring of instrumentation. Flux data were processed using EddyPro Advanced (v3.0.0beta, LI-COR) following standard procedures, including despiking of raw data, correction for angle of attack, time-lag compensation by seeking maximum covariance, double coordinate rotation, correction of sonic temperature for humidity, high- and low-frequency spectral corrections (Moncrieff et al., 1997) and the density corrections of Webb et al. (1980). No adjustment was made to account for instrument surface heating of the open-path IRGA; however, the relatively mild UK climate means this effect is not expected to be significant (Thomas et al., 2011). Subsequent quality control programs written in R (The R Foundation for Statistical Computing) exclude data collected at times of instrument malfunction and/or bad diagnostic values (LI-7500 output), when rain or 
moisture could adversely affect readings (particularly from the IRGA), and if data fell outside physically reasonable thresholds.

Data are analysed from installation on 9 May 2011 to 30 April 2012 (so May 2011 data are not complete). Of the potential $1714530 \mathrm{~min}$ periods, 97 are missing due to power failure. After quality control $96 \%$ of $Q_{\mathrm{H}}, 74 \%$ of $Q_{\mathrm{E}}$ and $73 \%$ of $F_{\mathrm{C}}$ data are available for analysis. A significant proportion of IRGA data loss was due to the high frequency of wet instrument windows because of rainfall. No friction velocity screening was used here, but $u_{*}$ values $<0.1 \mathrm{~m} \mathrm{~s}^{-1}$ were observed for less than $4 \%$ of the dataset, so the impact on the overall results is likely very small. Data failing the stationarity and developed turbulence tests of Foken and Wichura (1996) were not excluded from analysis as other studies have shown that the integral turbulence characteristics tests in particular may be too restrictive for urban areas (Fortuniak et al., 2013). This decision has a small effect on the fluxes: the magnitude of $Q_{\mathrm{H}}$ and $Q_{\mathrm{E}}$ monthly means would be increased by $0-3 \mathrm{~W} \mathrm{~m}^{-2}$ if these values were excluded. The biggest impact is on the friction velocity: the distribution is shifted to larger values (mean increases by $0.03 \mathrm{~m} \mathrm{~s}^{-1}$ ), more so at night (mean increases by $0.05 \mathrm{~m} \mathrm{~s}^{-1}$ ).

In the urban environment the available energy can be supplemented by heat released from anthropogenic activities such as building heating, traffic and human metabolism. Although difficult to measure directly, the anthropogenic heat flux can be estimated using statistical information and inventories relevant to the study area (Sailor and $\mathrm{Lu}, 2004$; Bergeron and Strachan, 2010). The release of $\mathrm{CO}_{2}$ from the associated combustion processes can also be estimated via the same method. Details of the methodology used for Swindon are given in Appendix A.

Given the complexities of direct measurements of the storage heat flux (Offerle et al., 2005a; Roberts et al., 2006), two alternative methods are used here: $\Delta Q_{\mathrm{S}}$ is estimated using the objective hysteresis model (OHM) of Grimmond et al. (1991) (see Appendix B), and the residual term $\left(\operatorname{RES}=\left(Q^{*}+Q_{\mathrm{F}}\right)-\left(Q_{\mathrm{H}}+Q_{\mathrm{E}}\right)\right)$ is calculated. Using RES as an estimate of the storage flux assumes closure of the energy balance at the time interval of estimation and collects all the errors in the other terms. The lack of energy balance closure in other environments is well documented measurement under-closure of $10-20 \%$ is common (Wilson et al., 2002). This has been partially attributed to ignoring heat storage, especially in forests (Leuning et al., 2012), as well as to underestimation of $Q_{\mathrm{H}}$ and $Q_{\mathrm{E}}$ by eddy covariance measurements (Wilson et al., 2002; Foken, 2008). Thus, if RES is used as a proxy for storage it should be taken as an upper limit (Coutts et al., 2007b; Bergeron and Strachan, 2010).

\section{Meteorological conditions during the study period}

Swindon generally experiences warm summers and cool wet winters. Southern England is drier than the UK as a whole - the Met Office normal annual rainfall for central and southeast England (1971-2000) is $780 \mathrm{~mm}$. Recent summers have been wet and cloudy, with more favourable weather in spring and/or autumn. The period May 2011 to April 2012 followed this trend. Spring 2011 was warm and sunny with less than a third of normal rainfall $(50 \mathrm{~mm}$ in March-May compared to the 1971-2000 normal $160 \mathrm{~mm}$ (at nearby Met Office station at Lyneham)). Summer 2011 was slightly cooler than normal with rain events occurring as frequent showers rather than intense downpours. Autumn was warm, with a warm and sunny spell from the end of September to early October (Fig. 3b). Slightly above normal temperatures continued through winter; with heavy frost in late January and snow in February 2012 (the longest period of snow cover was 2-3 days). February and March were dry with warm sunny weather from the end of March to early April, after which over three times the normal rain fell in Swindon (Fig. 3f) accompanied by low temperatures (Fig. 3b), and April 2012 became the wettest on UK records. The diurnal patterns of temperature, vapour pressure deficit (VPD) and wind speed were typical, with the highest values in the middle of the day and the expected inverse in relative humidity (RH) (data not shown). The prevailing wind is from the southwest quadrant (59\% of all data, Fig. 3e) and the next most common wind directions are from the northeast $(16 \%)$ and northwest $(15 \%)$.

\section{Results and discussion}

\subsection{Energy balance}

The net all-wave radiation provides energy to the surface that can be transformed into turbulent sensible or latent heat or stored in the urban fabric. For the data collected here, $\Delta Q_{\mathrm{S}}$ constitutes $19 \%$ of daily $Q^{*}$, whilst $Q_{\mathrm{H}}$ constitutes $45 \%$ and $Q_{\text {E }} 34 \%$ in June 2011. The coloured bars in Fig. 4 represent monthly averages calculated using all available data, whereas the unfilled bars indicate times when data for all energy fluxes are available concurrently. The main restriction is the availability of $Q_{\mathrm{E}}$ so this flux does not change, but average $Q^{*}$ and $Q_{\mathrm{H}}$ both increase if the averages are calculated for times when all energy fluxes are available, i.e. mainly excluding times during and following rainfall when there are no $Q_{\mathrm{E}}$ data. Data availability had the biggest impact in April 2012, when frequent rainfall significantly reduced the number of $Q_{\mathrm{E}}$ data points.

$Q^{*}$ is the largest flux except for November to January (Fig. 4), when solar radiative input is at a minimum. The peak in median diurnal $Q^{*}$ is about $470 \mathrm{~W} \mathrm{~m}^{-2}$ in June compared to $80 \mathrm{~W} \mathrm{~m}^{-2}$ in December (Fig. 5a). Warmer surfaces create 


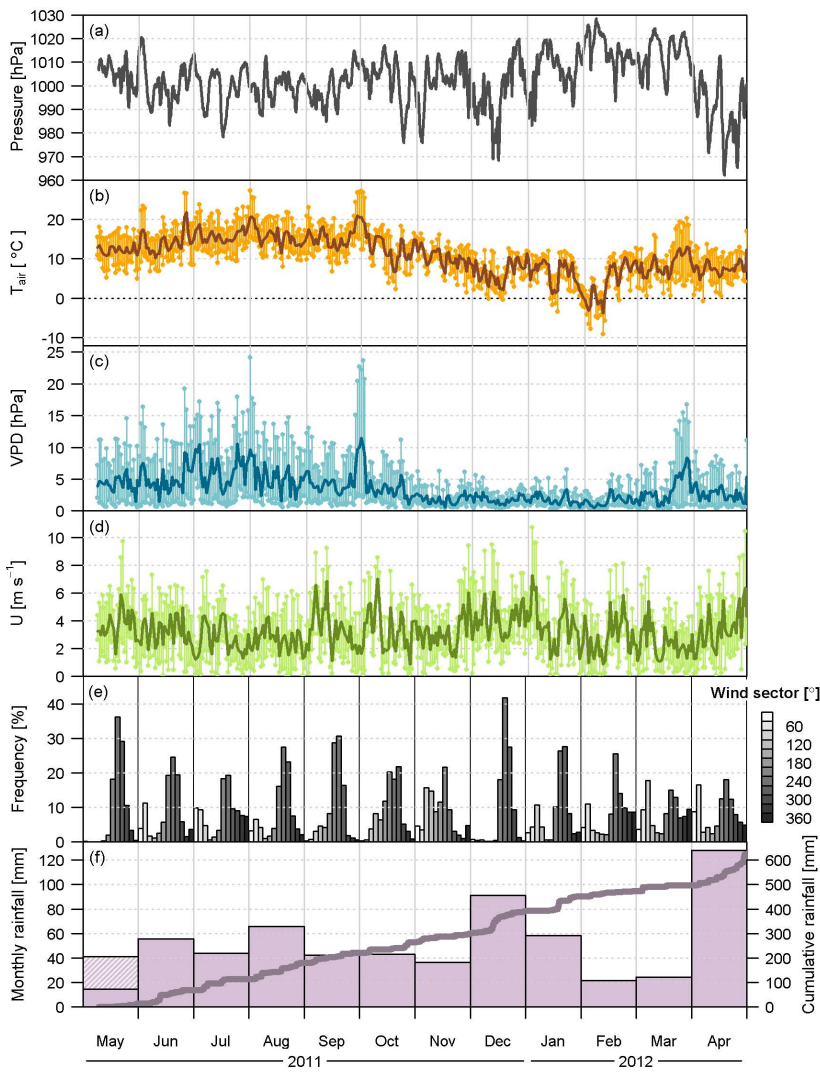

Fig. 3. Meteorological conditions during the study period: (a) mean station pressure; daily mean, maximum and minimum (b) air temperature; (c) vapour pressure deficit (VPD); (d) wind speed; (e) frequency distribution of $30 \mathrm{~min}$ wind direction by month; (f) cumulative and monthly rainfall totals. In (f) the hatched bar represents rainfall during May 2011 before the start of this dataset (measured in central Swindon $\left(51^{\circ} 34^{\prime} 0.3^{\prime \prime} \mathrm{N}, 1^{\circ} 47^{\prime} 5.3^{\prime \prime} \mathrm{W}\right)$ ).

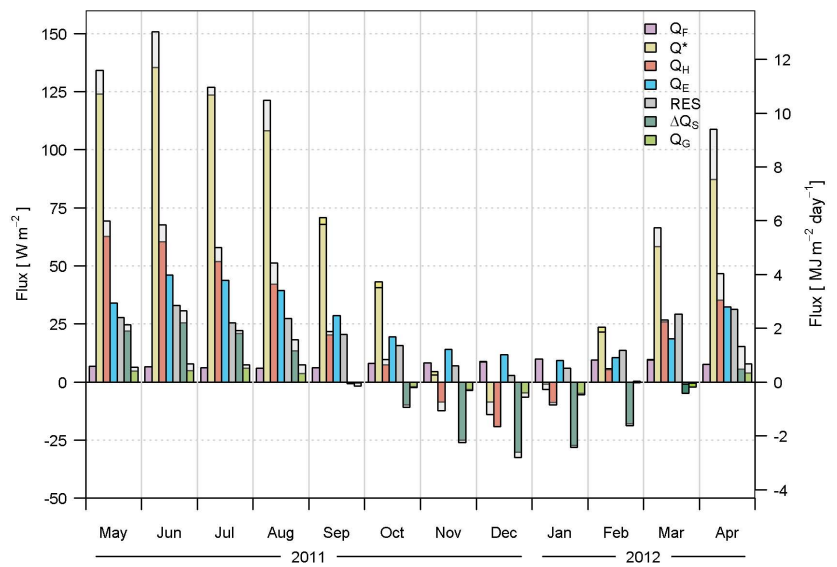

Fig. 4. Monthly mean fluxes (average of $24 \mathrm{~h}$ ensemble median values for each month) for all available data (coloured bars) and for concurrent data only (unfilled bars). RES denotes the residual $\left(Q^{*}+Q_{\mathrm{F}}\right)-\left(Q_{\mathrm{H}}+Q_{\mathrm{E}}\right)$.

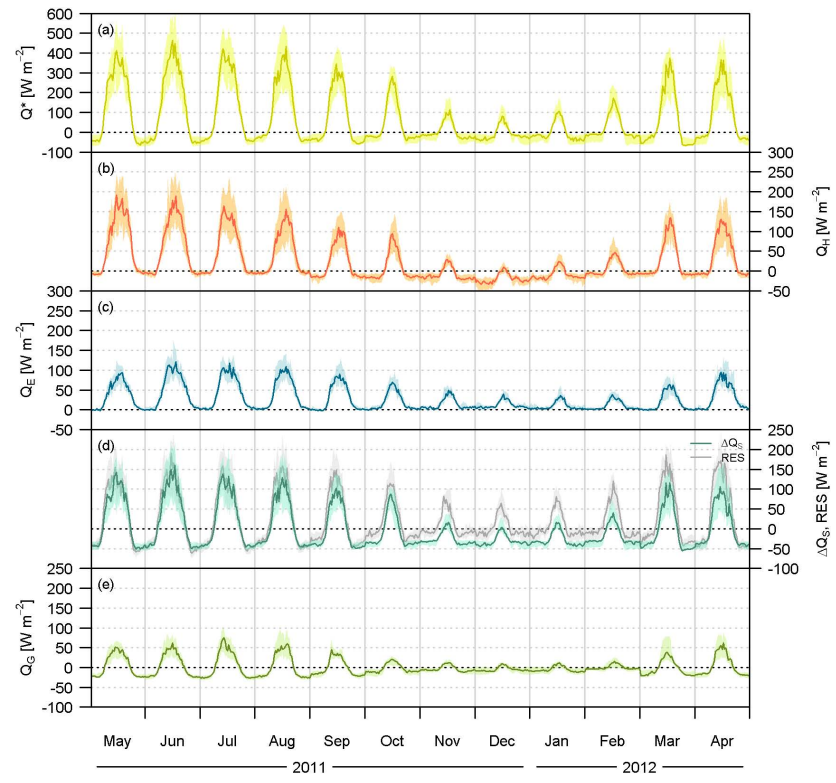

Fig. 5. Median diurnal cycles (lines) and interquartile ranges (shading) of the energy fluxes for the study period.

a larger nocturnal $Q^{*}$ loss in summer than winter. The size of $Q_{\mathrm{F}}$ is small but non-negligible, especially in winter, when the demand for central heating of buildings is largest and $Q^{*}$ smallest (Fig. 4). Monthly mean values of $6-10 \mathrm{~W} \mathrm{~m}^{-2}$ are smaller than estimates from other city-based UK studies: $Q_{\mathrm{F}}$ is estimated at $16-24 \mathrm{~W} \mathrm{~m}^{-2}$ across Greater London (Allen et al., 2011), with typical mean city-centre values of $18-150 \mathrm{~W} \mathrm{~m}^{-2}$ (Hamilton et al., 2009), and at $44 \mathrm{~W} \mathrm{~m}^{-2}$ in Edinburgh during October and November 2000 (Nemitz et al., 2002). However, the Swindon values agree reasonably well with suburban studies elsewhere (Christen and Vogt, 2004; Bergeron and Strachan, 2010).

The contribution from building energy use $\left(Q_{\mathrm{B}}\right)$ varies according to season whilst human metabolism $\left(Q_{\mathrm{M}}\right)$ and vehicle emissions $\left(Q_{\mathrm{V}}\right)$ form a fairly constant contribution to $Q_{\mathrm{F}}$ throughout the year (Fig. 6). The morning rush-hour peak in $Q_{\mathrm{V}}$ coincides with a peak in domestic energy use as people get up and travel to work. A sharp morning peak in $Q_{\mathrm{F}}$ is produced, whereas later in the day a secondary rise in $Q_{\mathrm{V}}$ and then $Q_{\mathrm{B}}$ leads to a more distributed release of $Q_{\mathrm{F}}$ in the evenings. For the residential site in Swindon, road transport is estimated to be the most important contribution to the anthropogenic heat flux. It is not surprising that this differs from Bergeron and Strachan (2010), who found that $Q_{\mathrm{B}}$ formed the largest contribution to $Q_{\mathrm{F}}$ at both their urban and suburban sites in Montreal, given the colder winters in Canada. As for other studies, the contribution of human metabolism is small (approximately $5 \%$ during daytimes and up to $25 \%$ during summer nights - less than $1 \mathrm{~W} \mathrm{~m}^{-2}$ in absolute terms). 


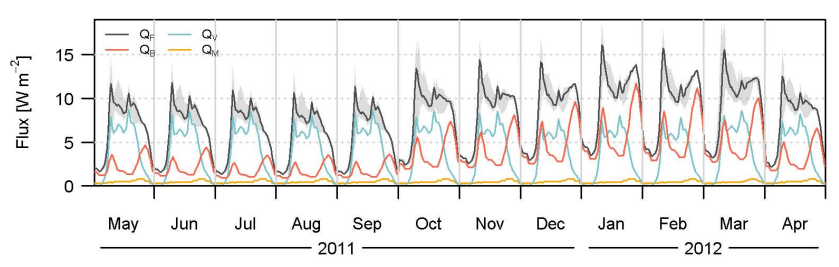

Fig. 6. Mean diurnal cycles of building energy use $\left(Q_{\mathrm{B}}\right)$, vehicle emission $\left(Q_{\mathrm{V}}\right)$ and human metabolism $\left(Q_{\mathrm{M}}\right)$ contributions to total anthropogenic heat flux $\left(Q_{\mathrm{F}}\right)$ for the study period (see Appendix A for details). Shading indicates maximum and minimum $Q_{\mathrm{F}}$ values.

Physically, the net storage heat flux is expected to be positive during summer and negative during winter so that annually there is minimal net gain or release of energy by the surface (Grimmond et al., 1991). The soil heat flux $\left(Q_{G}\right)$ is one component of the storage flux measured in this study. It shows the expected behaviour at daily and annual timescales, whereas RES remains positive all year round (Fig. 4). The residual data are biased to when all observed variables are available and most notably by the absence of data during and immediately following precipitation. It seems unlikely that this is the sole explanation here, although Kawai and Kanda (2010) observed enhanced release of stored energy on rainy days. In the summertime RES behaves like the storage flux, rising rapidly in the morning with $Q^{*}$ and being of similar magnitude to other studies. The residual has been used as an estimate of storage for several suburban locations in the USA (Grimmond and Oke, 1995; Balogun et al., 2009). In winter, however, RES is considerably larger than $\Delta Q_{\mathrm{S}}$ during daytime and less negative at night (Fig. 5d), resulting in a daily total RES that remains positive in winter in contrast to $\Delta Q_{\mathrm{S}}$ and $Q_{\mathrm{G}}$. The use of OHM to estimate $\Delta Q_{\mathrm{S}}$ in Vancouver by Grimmond (1992) also suggested no significant annual gain in energy by the surface and a net release of stored heat over $24 \mathrm{~h}$ in winter. However, according to Fig. 5d, OHM suggests a large release of stored energy during winter which does not appear as outgoing radiation, $Q_{\mathrm{H}}$ or $Q_{\mathrm{E}}$ and so is not physically justified. Whilst the energy balance closure is close to $100 \%$ in summer, it is over-closed by about $20 \%$ in winter. That $\Delta Q_{\mathrm{S}}$ changes sign at similar times to $Q_{\mathrm{G}}$ gives some support to the OHM estimates, but there is also a clear decrease in the magnitude of nocturnal $Q_{\mathrm{G}}$ from summer through to winter which is not replicated by OHM. This is mainly due to the negative $a_{3}$ term in the $\Delta Q_{\mathrm{S}}$ estimation (see Appendix B) which seems to be too large during winter, although studies are limited. Clearly, there is a need for more winter-based evaluations of OHM (Best and Grimmond, 2013) and for more wintertime field campaigns to improve estimates of $\Delta Q_{\mathrm{S}}$.

Of the turbulent heat fluxes, $Q_{\mathrm{H}}$ is largest in May, whilst $Q_{\text {E }}$ peaks in June along with $Q^{*}$ (Fig. 4). During the winter, when $Q^{*}$ is negative so is $Q_{\mathrm{H}}$, whereas mean daily $Q_{\mathrm{E}}$ remains clearly positive throughout the year. The exception is small negative values of $Q_{\mathrm{E}}$ that are sometimes observed at night (around $15 \%$ of all data) when the latent heat flux is directed towards the surface, i.e. dewfall. Generally, $Q_{\mathrm{E}}$ remains close to and slightly above zero during nighttime (mean $5.7 \mathrm{~W} \mathrm{~m}^{-2}$, median $3.4 \mathrm{~W} \mathrm{~m}^{-2}$ ), as also documented in other suburban studies (Grimmond and Oke, 1995; Balogun et al., 2009). Average nighttime values are largest during winter, peaking in November-December, and are also quite high in July. However, given the small size of the signal, the relative uncertainty in these data can be significant: the majority of nighttime values lie between -15 and $15 \mathrm{~W} \mathrm{~m}^{-2}$, similar in size to the uncertainty (the larger of $15 \%$ of $Q_{\mathrm{E}}$ or $15 \mathrm{~W} \mathrm{~m}^{-2}$, according to Mauder et al., 2006).

The diurnal course of the sensible heat flux changes considerably with season, from being large and positive during daytime and small and negative at night (May to August), to remaining below zero (around $-25 \mathrm{~W} \mathrm{~m}^{-2}$ ) and only reaching positive values for a few hours around midday (December) (Fig. 5b). Such negative $Q_{\mathrm{H}}$ values are seen when the fraction of built-up area is small, but these observations are rare in the literature. Rather, the focus has been either for warm periods or more heavily urbanised areas, where there is a larger anthropogenic energy input and release of energy from storage (Nemitz et al., 2002; Offerle et al., 2005a; Loridan and Grimmond, 2012). Recent results from a suburban site in Oberhausen, Germany, show similar wintertime behaviour to that observed in Swindon (Goldbach and Kuttler, 2013), supporting the idea that the sensible heat flux becomes more negative in winter and at night with decreasing building density.

Of particular interest is the changing relation between $Q_{\mathrm{H}}$ and $Q_{\mathrm{E}}$ (i.e. the Bowen ratio, $\beta$ ). In summer, when solar radiation provides energy for warming the atmosphere and evaporation, the turbulent heat fluxes are largest with more energy directed into heating the air than evaporation (June median diurnal peaks at 189 and $121 \mathrm{~W} \mathrm{~m}^{-2}$, respectively, giving a Bowen ratio of 1.6). Both $Q_{\mathrm{H}}$ and $Q_{\mathrm{E}}$ decrease through autumn into winter, $Q_{\mathrm{E}}$ remains positive and begins to dominate the increasingly negative $Q_{\mathrm{H}}$ so that in autumn and winter more energy is partitioned into $Q_{\mathrm{E}}$ than $Q_{\mathrm{H}}$ and $\beta$ drops below 1 . This demonstrates an important difference in behaviour to the bulk of studies of suburban environments and is discussed in more detail in Sect. 5.2.

\subsection{Controls on evaporation}

For urban areas with similar vegetation fractions, the literature suggests typical midday or daytime Bowen ratios of 1-1.5 (Grimmond and Oke, 1995; Loridan and Grimmond, 2012). This is indeed matched quite well during summer 2011 in Swindon. However, midday $( \pm 2 \mathrm{~h})$ Bowen ratio values range from above 2.0 in spring to close to 0.5 in winter with a minimum of 0.05 in December when $Q_{\mathrm{H}}$ is at a minimum (Fig. 7a). The range in daytime $\left(K_{\downarrow}>5 \mathrm{~W} \mathrm{~m}^{-2}\right)$ Bowen ratios is greater and, as a result of the negative 

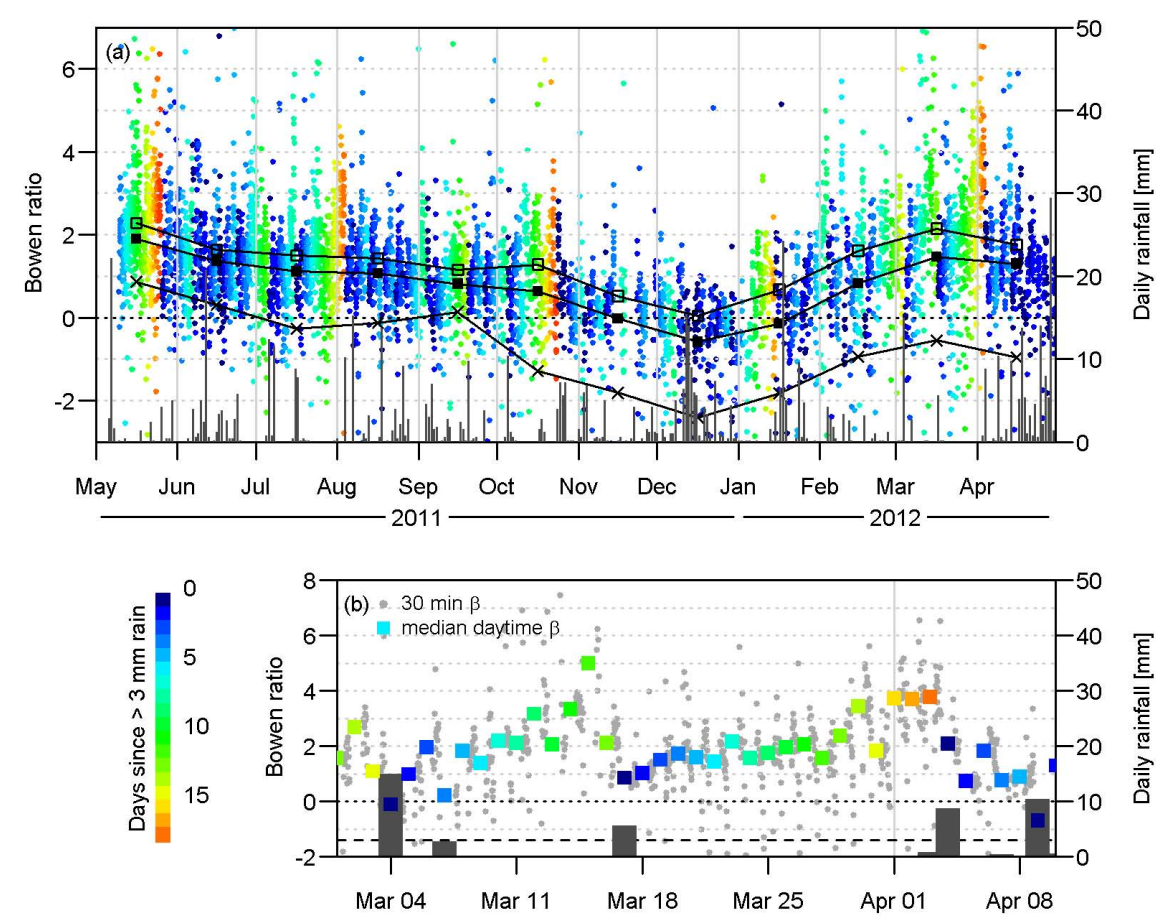

Fig. 7. Daytime $\left(K_{\downarrow}>5 \mathrm{~W} \mathrm{~m}^{-2}\right.$ ) Bowen ratio $(30 \mathrm{~min}$ ) coloured by number of days since rainfall (exceeding $3 \mathrm{~mm}$ ) for (a) the study period and (b) spring 2012. Daily rainfall (bars) corresponds to the right-hand axes. In (a) monthly median midday ( $\pm 2 \mathrm{~h}$ ) (open squares), monthly median daytime (solid squares) and monthly median nighttime $\left(Q^{*}<0\right.$ and $K_{\downarrow} \leq 5 \mathrm{~W} \mathrm{~m}^{-2}$ ) (crosses) Bowen ratios are plotted mid-month. In (b) the median daytime Bowen ratios for each day are shown (coloured squares).

sensible heat flux except during the middle of the day, $\beta$ is negative November-January, dropping to -0.6 in December. Nocturnal Bowen ratios are lower and more variable but follow a similar monthly pattern to the daytime values. They are often negative because $Q_{\mathrm{H}}<0 \mathrm{~W} \mathrm{~m}^{-2}$.

Rainfall was frequent in the second half of 2011 (Sect. 4). The longest dry periods were in mid-May 2011, following a very dry spring, and at the end of March 2012. The highest midday Bowen ratios occurred during the driest conditions (May 2011, end of July and mid-October 2011, March 2012, Fig. 7a) with frequent individual 30-min $\beta$ values $>4$. Fig. 7b shows spring 2012 in more detail. February 2012 was drier than normal, and in March less than one third of the average rainfall was recorded (Sect. 4). The Bowen ratio is seen to respond to the availability of water on a daily timescale, ramping up from $<1$ following rainfall to $>4$ as the surface dries out. Although the wind direction changes during this period, expected trends with vegetation fraction seem to be overridden by the limited availability of water i.e. water supply is more important than surface cover in this case. After heavy rain on 3 April, median daytime $\beta$ is mostly between 0 and 2 for the rest of the month, with a decreasing trend overall as extended rains provide abundant surface water and replenish soil moisture (not shown). Although not shown here, the remainder of 2012 was very wet and soil moisture remained high in contrast to 2011. As a result, observed Bowen ratios were lower during summer 2012 than 2011 (closer to 1 than 1.5).

Observed $Q_{\mathrm{E}}$ can be compared to the equilibrium evaporation, $Q_{\mathrm{Eq}}$ (Slatyer and McIlroy, 1961) for urban areas:

$Q_{\mathrm{Eq}}=\frac{s}{s+\gamma}\left(Q^{*}+Q_{\mathrm{F}}-\Delta Q_{\mathrm{S}}\right)$,

where $s$ is the slope of the saturation vapour pressuretemperature curve and $\gamma$ is the psychrometric constant. $Q_{\mathrm{Eq}}$ is the energy limited but water unlimited evaporation rate for the ambient conditions. Note that since the $\Delta Q_{\mathrm{S}}$ term is calculated here using OHM, it is also a function of $Q^{*}$. If instead the residual is used, then the bracketed term reduces to the sum of the turbulent fluxes $\left(Q_{\mathrm{H}}+Q_{\mathrm{E}}\right)$. The ratio $Q_{\mathrm{E}} / Q_{\mathrm{Eq}}$ is the Priestley-Taylor aridity parameter $\left(\alpha_{\mathrm{PT}}\right)$. For saturated surfaces (abundant moisture) $\alpha_{\mathrm{PT}}=1.26$ and represents potential evaporation (Priestley and Taylor, 1972). Urban values of $\alpha_{\mathrm{PT}}$ are considerably lower, e.g. 0.51 in humid Miami (Newton et al., 2007) and between 0.5 for well-irrigated suburban areas (Sacramento, California; Chicago, Illinois) and 0.1 for unusually dry conditions in Vancouver during an irrigation ban (Grimmond and Oke, 1999c). For Swindon in March-April 2012, $\alpha_{\mathrm{PT}}=$ 0.52 . The low rainfall in early spring and increasingly dry conditions resulted in a marked reduction in $\alpha_{\mathrm{PT}}$, from 0.56 at $12-24 \mathrm{~h}$ after rainfall to 0.28 during the longest dry period 


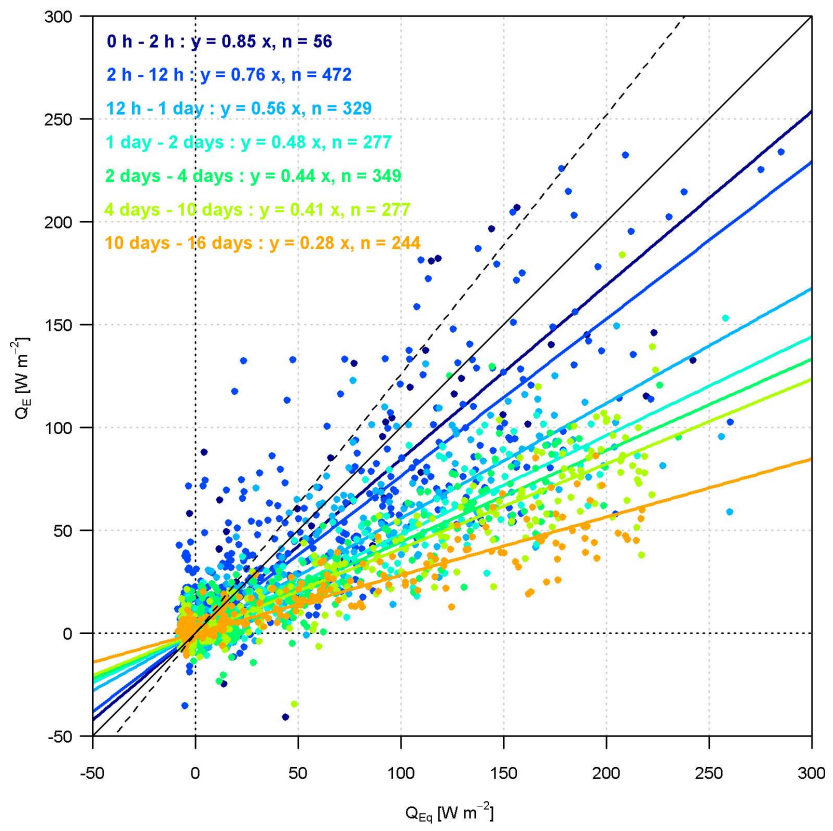

Fig. 8. Measured evaporation ( $30 \mathrm{~min}$ ) against equilibrium evaporation for contrasting water availability in March and April 2012, coloured according to time since rainfall. The slopes give the value of $\alpha_{\mathrm{PT}}: 1.26$, i.e. potential evaporation (dashed line), 1.00 (solid black line) and decreasing $\alpha_{\mathrm{PT}}$ with increasing time since rain (coloured, inset).

10-16 days after rain (Fig. 8). Despite the uncertainties in the energy balance terms, in particular $\Delta Q_{\mathrm{S}}$, the observed trend remains when the available energy is increased or decreased (adjusting $\Delta Q_{\mathrm{S}}$ by $\pm 10 \%$ spreads the $\alpha_{\mathrm{PT}}$ values by \pm 0.03$)$. For this period, $Q_{\mathrm{E}}$ demonstrates a clear and strong response to surface moisture availability, even with source areas sometimes from the more treed sectors.

The measured suburban evaporation is well below the equilibrium value, implying that there is some control due to limited water supply even a few hours after rainfall (e.g. $\alpha_{\mathrm{PT}}=0.76$ for $2-12 \mathrm{~h}$, Fig. 8). This conforms to expectations given the enhanced proportion of impervious surfaces, smaller vegetation fraction and reduced water storage compared to most natural environments. However, directly following rainfall, measured $Q_{\mathrm{E}}$ is significantly greater than $Q_{\mathrm{Eq}}$ (points $>1: 1$ line in Fig. 8). For these instances $Q_{\mathrm{E}}$ is larger than would be expected given the available energy and likely represents rapid evaporation from rainfall that has either been intercepted by vegetation or buildings, or reached impervious road surfaces, that may be enhanced by micro-scale advection. Particularly if a warm, dry, impervious surface is suddenly wetted, energy is primarily directed into evaporation and $Q_{\mathrm{E}}$ can exceed $Q^{*}$ via a negative $Q_{\mathrm{H}}$ as heat is supplied from the surroundings. For example, following a rain shower at 12:00 UTC on 5 June 2011, $\beta$ dropped from around 1.5 to -0.5 and $Q_{\mathrm{H}}$

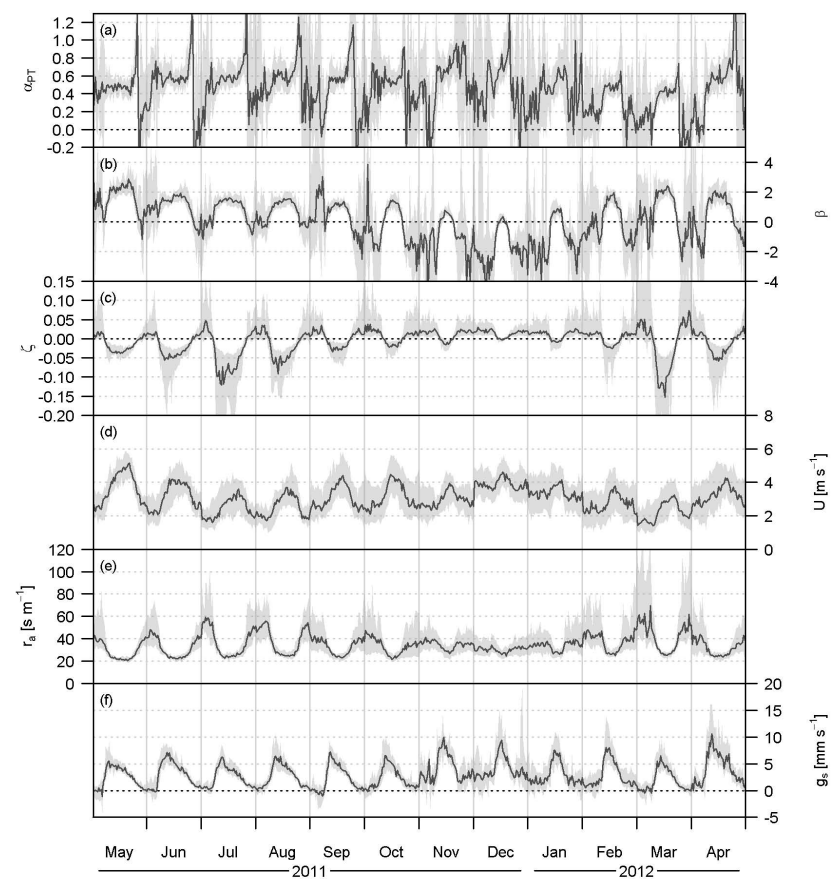

Fig. 9. Monthly median diurnal cycles (lines) and interquartile ranges (shading) of (a) the aridity parameter, $\alpha_{\mathrm{PT}} ;$ (b) Bowen ratio, $\beta$; (c) stability parameter, $\zeta$; (d) wind speed, $U$; (e) aerodynamic resistance, $r_{\mathrm{a}}$; and (f) surface conductance, $g_{\mathrm{s}}$, for all conditions. See text for methods.

remained negative throughout the afternoon (between -32 and $-1 \mathrm{~W} \mathrm{~m}^{-2}$ ). These sudden large water vapour fluxes are an important part of the urban water budget, but are problematic to measure with open-path gas analysers (as instrument windows may remain wet for as long as the urban surface) and difficult to quantify through simple models.

There is also a considerable proportion of nighttime data when $Q_{\mathrm{E}}>Q_{\mathrm{Eq}}$ with small positive or negative values even when water is limited (i.e. many days after rain). This may result from inaccuracies in the nighttime storage heat flux. Uncertainties are likely to be small for $Q^{*}(<5 \%$, e.g. Blonquist Jr. et al., 2009) but appreciable for observed $Q_{\mathrm{E}}$ (Sect. 5.1), and at these times $\alpha_{\mathrm{PT}}$ is the ratio of two small numbers. Note, however, that exclusion of the nighttime data does not significantly change the regression slopes.

Despite clear trends in Fig. 8 there is considerable scatter. Crudely accounting for a measure of water availability and applying this available energy-based estimation captures some of the trends in $Q_{\mathrm{E}}$, but it does not accurately represent its variability. Also, in Fig. 9a, the lack of a diurnal trend in $\alpha_{\mathrm{PT}}$ suggests a significant dependence on the energy available and supports the suggestion that the general model of $Q_{\mathrm{E}}$ responding to $Q^{*}+Q_{\mathrm{F}}-\Delta Q_{\mathrm{S}}$ is well replicated across the daily timescale. Other relevant controls depend on the timescale of interest, e.g. water availability through soil moisture usually changes over days to weeks, whereas 
radiative forcing can change over minutes when cloud cover is patchy. The peaks in $\alpha_{\mathrm{PT}}$ towards the end of the day result from $Q_{\mathrm{Eq}}$ values passing through zero, and there is considerable variability associated with small fluxes at transition times and at night. After the very dry start to April 2012, the month as a whole was very wet (Sect. 4) and produced a relatively large value of $\alpha_{\mathrm{PT}}(0.6-0.7)$ (Fig. 9a). Evaporation was closest to equilibrium rates in November-December 2011, when there was fairly frequent, sometimes heavy, rain and minimum solar energy input so that surfaces remained wet for much of the time. Due to the increased difficulties of estimating $\Delta Q_{\mathrm{S}}$ at this time, we suspect that the "true" $\alpha_{\mathrm{PT}}$ may be larger than shown here.

The seasonal variability of $Q_{\mathrm{E}}$ in relation to the available energy $\left(\alpha_{\mathrm{PT}}\right)$ differs from the relation to $Q_{\mathrm{H}}(\beta)$. The Bowen ratio has a clear diurnal cycle throughout the year (Fig. 9b) and, again, nighttime results are highly variable being the ratio of small numbers (with appreciable uncertainties: the uncertainty on $Q_{\mathrm{H}}$ being the larger of $10 \%$ or $10 \mathrm{~W} \mathrm{~m}^{-2}$; Mauder et al., 2006). Negative $\beta$ values for much of winter daytime reflects the tendency for $Q_{\mathrm{H}}<0 \mathrm{~W} \mathrm{~m}^{-2}$ (Fig. 5) and prevailing stable or near-neutral conditions. The small values of the stability parameter, $\zeta=\left(z_{\mathrm{m}}-z_{\mathrm{d}}\right) / L_{\mathrm{Ob}}\left(L_{\mathrm{Ob}}\right.$ is the Obukhov length), even during spring and summer, appear perhaps surprising at first (Fig. 9c). However, they are consistent with other studies (Weber and Kordowski, 2010) and are likely further suppressed by the wet conditions for this dataset; outside summer, dry March 2012 was fairly unstable. A combination of lower suburban $Q_{\mathrm{H}}$ than city centres (less heavily urbanised, more vegetation), but often similar displacement heights, means that suburban $\zeta$ can be low compared to both more urbanised and rural sites. This is exemplified by three sites along an urbanisation gradient in Montreal, Canada (Bergeron and Strachan, 2010).

The Penman-Monteith equation allows the calculation of the latent heat flux by incorporating the resistance of the surface (Monteith, 1965) and can therefore be applied in cases where water is not freely available. Grimmond and Oke (1991) modified the equation for urban areas:

$Q_{\mathrm{E} \_\mathrm{PM}}=\frac{s\left(Q^{*}+Q_{\mathrm{F}}-\Delta Q_{\mathrm{S}}\right)+\rho c_{\mathrm{p}} \mathrm{VPD} / r_{\mathrm{a}}}{s+\gamma\left(1+r_{\mathrm{s}} / r_{\mathrm{a}}\right)}$,

where $\rho$ is the density of air, $c_{\mathrm{p}}$ the specific heat capacity of air, VPD the vapour pressure deficit, $r_{\mathrm{a}}$ the aerodynamic resistance and $r_{\mathrm{s}}$ the surface resistance. The aerodynamic resistance in Eq. (3) should be that for heat and water vapour (assumed equal) and can be calculated via (Grimmond and Oke, 1991)

$r_{\mathrm{a}}=\frac{\left[\ln \left(\frac{z_{\mathrm{m}}-z_{\mathrm{d}}}{z_{0 m}}\right)-\psi_{m}\right]\left[\ln \left(\frac{z_{\mathrm{m}}-z_{\mathrm{d}}}{z_{0 v}}\right)-\psi_{v}\right]}{\kappa_{v}^{2} U}=\frac{\left[\ln \left(\frac{z_{\mathrm{m}}-z_{\mathrm{d}}}{z_{0 v}}\right)-\psi_{v}\right]}{\kappa_{v} u_{*}}$,

where $\kappa_{v}$ is von Kármán's constant (0.4), $U$ the horizontal wind speed, $u_{*}$ the friction velocity and $\Psi$ are stability functions for momentum (subscript $m$ ) or heat and water vapour (subscript $v$ ) (van Ulden and Holtslag, 1985; Högström, 1988). Here, the right-hand form of Eq. (4) is used with the EC measured $u_{*}$. Following Järvi et al. (2011), the roughness length for water vapour was estimated using (Brutsaert, 1982)

$z_{0 v}=z_{0 m} \exp \left[2-a\left(\frac{u_{*} z_{0 m}}{v}\right)^{0.25}\right]$,

where $v$ is the molecular viscosity of air, with the surfacedependent coefficient calculated using the parameterisation suggested by Kawai et al. (2009) for vegetated cities,

$a=\left(1.2-0.9 \lambda_{V}^{0.29}\right)$.

Aerodynamic resistances describe the impedance of scalars (momentum, heat, water vapour) to transfer by turbulence. Maximum $r_{\mathrm{a}}$ occurs when conditions are calm and mechanical turbulence is weak (wind speeds close to zero). Calculating $r_{\mathrm{a}}$ from Eq. (4) enables the surface resistance to be estimated from observed $Q_{\mathrm{E}}$ and $\beta$ (Monteith, 1965):

$r_{\mathrm{s}}=\left(\frac{s}{\gamma} \beta-1\right) r_{\mathrm{a}}+\frac{\rho c_{p} \mathrm{VPD}}{\gamma Q_{\mathrm{E}}}$.

The resulting $r_{\mathrm{s}}$ values are effectively a measurement of the surface resistance obtained by inversion of Eq. (3). For wet surfaces $r_{\mathrm{s}}$ approaches zero and $Q_{\mathrm{E}}$ is determined by the energy available. For dry conditions $r_{\mathrm{s}}$ comprises the mix of surface controls affecting $Q_{\mathrm{E}}$ and is a complex function of meteorological conditions and surface characteristics (e.g. incoming radiation, air temperature, humidity, wind speed, soil moisture, leaf area index; Järvi et al., 2011), analogous to the bulk canopy resistance in forests made up of leaf stomatal resistance and contributions from the understory. Since $r_{\mathrm{s}}$ encompasses the range of controls determining the transport of water vapour between the surface and atmosphere, it would be highly desirable to be able to correctly parameterise this variable. Resistance can also be expressed as its reciprocal the surface conductance, $g_{\mathrm{s}}=$ $r_{\mathrm{s}}^{-1}$.

Patterns in $r_{\mathrm{s}}$ are not always followed by those in $r_{\mathrm{a}}$, indicating that the surface resistance cannot be explained by aerodynamic controls alone. The aerodynamic resistance shows remarkably little variability during daytime and all months exhibit a clear diurnal cycle of minimum resistance in the middle of the day (Fig. 9e). Except during winter the daily cycle is smooth and fairly symmetrical. In contrast, the diurnal cycle of $g_{\mathrm{s}}$ is highly asymmetrical: surface conductance is usually highest in the morning and then reduces through the afternoon until close to zero at night (Fig. 9f), which emerges from the combined shape of $Q_{\mathrm{E}} / \mathrm{VPD}$ on a daily timescale. Nighttime conductances are significantly larger during winter than other seasons (around $3 \mathrm{~mm} \mathrm{~s}^{-1}$ compared to almost zero) when the surface often 

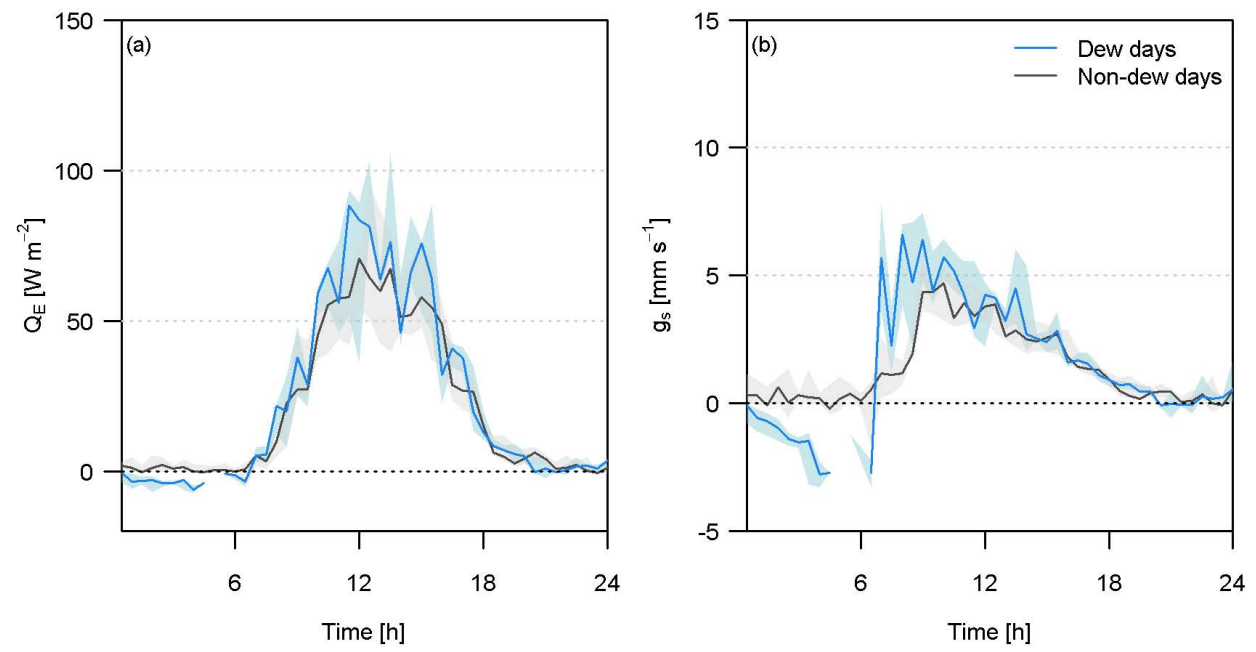

Fig. 10. Median diurnal cycles (lines) and interquartile ranges (shading) of (a) latent heat flux and (b) surface conductance for selected days with heavy dewfall (23-26, 30 March 2012) and little or no dewfall (22, 27-29, 31 March 2012, 1-2 April 2012). Values of $g_{\mathrm{s}}>40 \mathrm{~mm} \mathrm{~s}{ }^{-1}$ or $g_{\mathrm{s}}<-10 \mathrm{~mm} \mathrm{~s}^{-1}$ have been excluded.

remains wet, the anthropogenic energy input is greatest and nocturnal wind speeds are high (Fig. 9d). Uncertainty in the roughness length for momentum has a sizable effect on $r_{\mathrm{a}}$, but the impact on $g_{\mathrm{s}}$ is small: increasing $z_{0 m}$ by $0.5 \mathrm{~m}$ increases the median value of $r_{\mathrm{a}}$ by $1.8 \mathrm{~s} \mathrm{~m}^{-1}$ and the average difference is $6 \%$; the median value of $g_{\mathrm{s}}$ is unchanged and the average difference is $2 \%$.

During morning hours the behaviour of $g_{\mathrm{s}}$ differs for days with and without dewfall (days with dew were identified by the surface wetness sensor and IRGA diagnostics, Fig. 10). Negative $Q_{\mathrm{E}}$ during nighttimes with dew results in negative surface conductances. Whilst $Q_{\mathrm{E}}$ measurements are scarce when heavy dew settles on and is evaporated from the IRGA windows, the data remaining after quality control (i.e. when moisture is not present on the instrument windows but likely remains over the surroundings) indicate larger surface conductances in the early morning compared to days with little or no dewfall. By the afternoon, the course of $g_{\mathrm{s}}$ is similar for dew and non-dew days. Note that irrigation of gardens in Swindon is expected to be minimal, particularly overnight, unlike in many of the North American studies.

The dataset is divided into broad categories by season (summer (MJJA), autumn (SON), winter (DJF) and spring (MA)) and approximate wetness regimes (wet (1 to $6 \mathrm{~h}$ after rain), partially wet (6 $\mathrm{h}$ to 2 days after rain) and dry ( $\geq 2$ days since rain)). The largest $Q_{\mathrm{E}}$ values occur in spring and summer (Fig. 11a), when the leaf area index increases, vegetation actively transpires and solar radiation is large (Sect. 5.1). Potential evaporation rates are rarely reached during the day, even for wet conditions, although by selecting data between 1 and $6 \mathrm{~h}$ after rain, some of the highest evaporation rates immediately following rainfall have been excluded (these can be highly variable and confuse underlying trends). The wintertime potential evaporation is thought to be overestimated in Fig. 11a due to the limitations of the OHM estimation of $\Delta Q_{\mathrm{S}}$. For all seasons there is an appreciable difference between wet and dry conditions, with the most marked contrast in spring 2012, when rainfall patterns were extreme (Sect. 4).

Differences in synoptic conditions, particularly cloud cover and $Q^{*}$, lead to differences in the potential evaporation rates between wetness subsets: daily potential evaporation is larger for dry conditions than wet conditions, yet observed daily evaporation totals are smaller for dry conditions than wet conditions. In winter the potential evaporation is similar between subsets, at $0.87 \mathrm{~mm} \mathrm{day}^{-1}$ and $0.89 \mathrm{~mm} \mathrm{day}^{-1}$ for wet and dry conditions, respectively, whereas the observed evaporation was $0.53 \mathrm{~mm} \mathrm{day}^{-1}(61 \%)$ and $0.33 \mathrm{~mm} \mathrm{day}^{-1}$ $(38 \%)$, respectively. As expected, the greatest contrast is seen in March-April 2012, when observed evaporation reached $71 \%$ of potential for wet conditions and $28 \%$ for dry conditions. The largest mean daily evaporation rates were observed for summer $\left(1.89\right.$ and $\left.1.39 \mathrm{~mm} \mathrm{day}^{-1}\right)$, as also predicted by the potential rates $\left(3.10\right.$ and $3.33 \mathrm{~mm}$ day $^{-1}$ ) for both wet and dry conditions. On the whole, the potential evaporation shows the same seasonal trends as, but is much larger than, the observations and also the ratio of observed to potential evaporation varies considerably with season and surface conditions. This supports earlier findings that $\alpha_{\mathrm{PT}}$ is dynamic (Figs. 8 and 9a). In addition, Fig. 11b shows the dependence of the Bowen ratio on moisture availability for all seasons.

The surface conductance is significantly higher shortly after rainfall, when surfaces are likely to be wet, but Fig. 11c suggests that setting $r_{\mathrm{s}}$ to 0 during these times may be too extreme. Median values of $g_{\mathrm{s}}$ reach about $17-20 \mathrm{~mm} \mathrm{~s}^{-1}$ in spring and summer and $12-15 \mathrm{~mm} \mathrm{~s}^{-1}$ in autumn and winter for data $1-6 \mathrm{~h}$ after rain. For dry conditions the peak of 


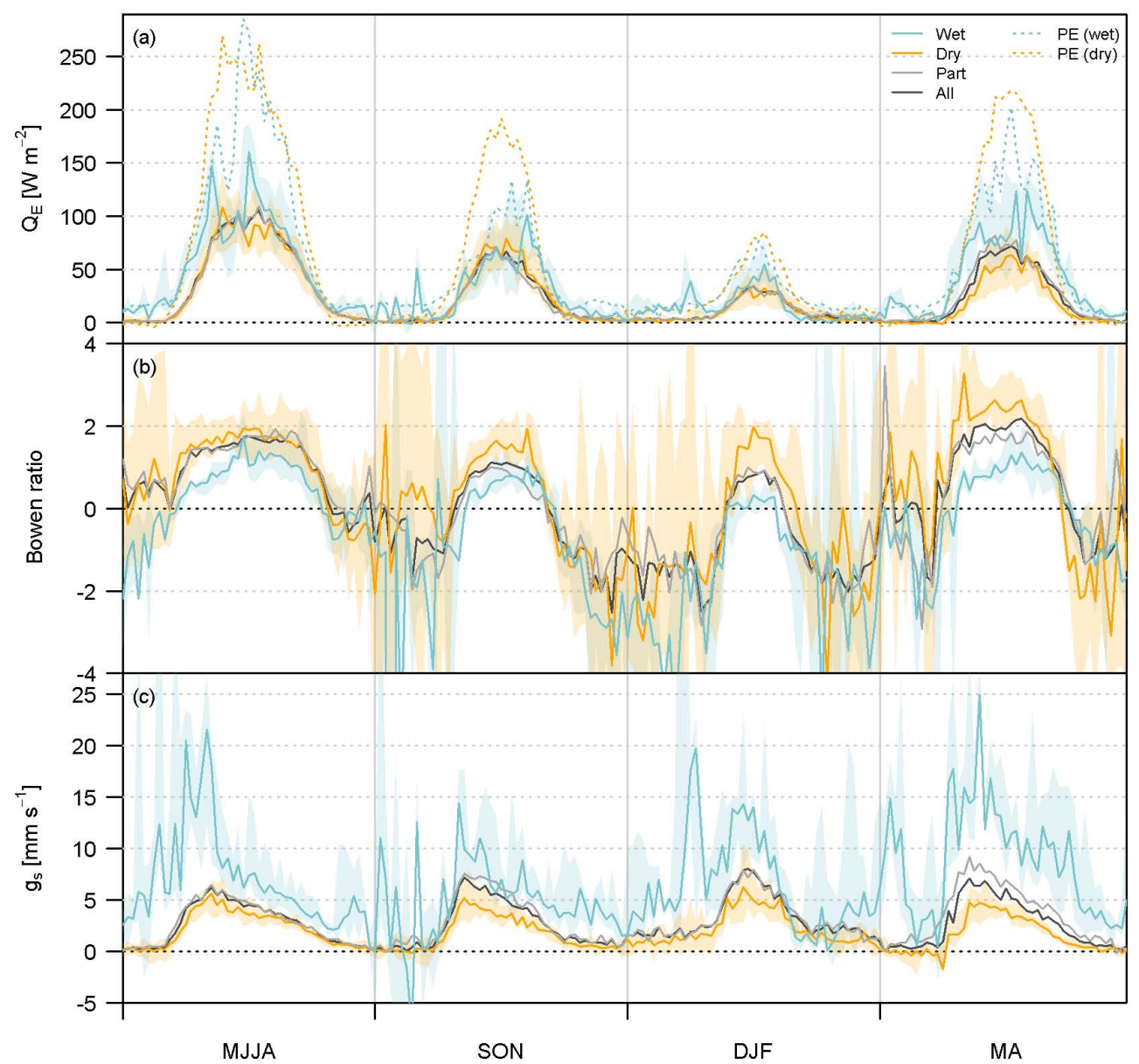

Fig. 11. Median diurnal cycles and interquartile ranges (shading) of (a) measured and potential evaporation (PE), (b) Bowen ratio and (c) surface conductance by season and for different surface conditions: wet ( 1 to $6 \mathrm{~h}$ after rain), partially wet (6h to 2 days after rain) and dry ( $\geq 2$ days since rain).

the diurnal cycle is around $5 \mathrm{~mm} \mathrm{~s}^{-1}$ (Fig. 11c). Although peak values are similar across all seasons $\left(6-9 \mathrm{~mm} \mathrm{~s}^{-1}\right.$ for all conditions) the shape of the diurnal pattern varies. Some monthly variability seen in Fig. 9f is averaged out across the seasons, such as the contrast in peak values between March and April 2012, whilst other trends remain visible, for example higher nighttime conductance in winter. Under wet conditions $Q_{\mathrm{E}}$ and $g_{\mathrm{s}}$ are highly variable and show sharp changes from hour to hour, in contrast to the fairly smooth behaviour, particularly during daytime, when the surface is dry.

\subsection{Carbon flux}

There are often distinct sources and sinks of $\mathrm{CO}_{2}$ with strong temporal signatures. Examples include natural processes such as seasonal and diurnal patterns of $\mathrm{CO}_{2}$ uptake by plants and $\mathrm{CO}_{2}$ release through respiration, as well as human drivers that include emissions from traffic, heating, industry or landfill sites. Carbon fluxes measured by eddy covariance above suburban areas are the net result of these surface controls.

There is a striking contrast between daytime $\mathrm{CO}_{2}$ uptake in summer and release in winter (Fig. 12). Summertime uptake by vegetation is largest in the middle of the day $\left(-5 \mu \mathrm{mol} \mathrm{m} \mathrm{m}^{-2} \mathrm{~s}^{-1}\right)$ and total $F_{\mathrm{C}}$ exhibits strong correlation with photosynthetically active radiation (PAR, estimated as a proportion of $K_{\downarrow}$ following Papaioannou et al. (1993), Fig. 13). Results are similar to those of Crawford et al. (2011) (see their Fig. 6): for high PAR values (around $1500 \mu \mathrm{mol} \mathrm{m}^{-2} \mathrm{~s}^{-1}$ ) the rate of uptake decreases, probably limited by stomatal closure and light saturation; for low PAR values the increase in uptake is more linear than the natural ecosystem comparisons. The Swindon fluxes are more positive (a larger source, smaller sink) than the natural ecosystem comparisons when reduced to similar vegetation fraction, demonstrating the impact of anthropogenic sources. Compared to the Baltimore site $\left(\lambda_{V}=0.67\right)$ (Crawford et al., 2011) the Swindon uptake is lower. Swindon has a smaller vegetative fraction, increased building density and 


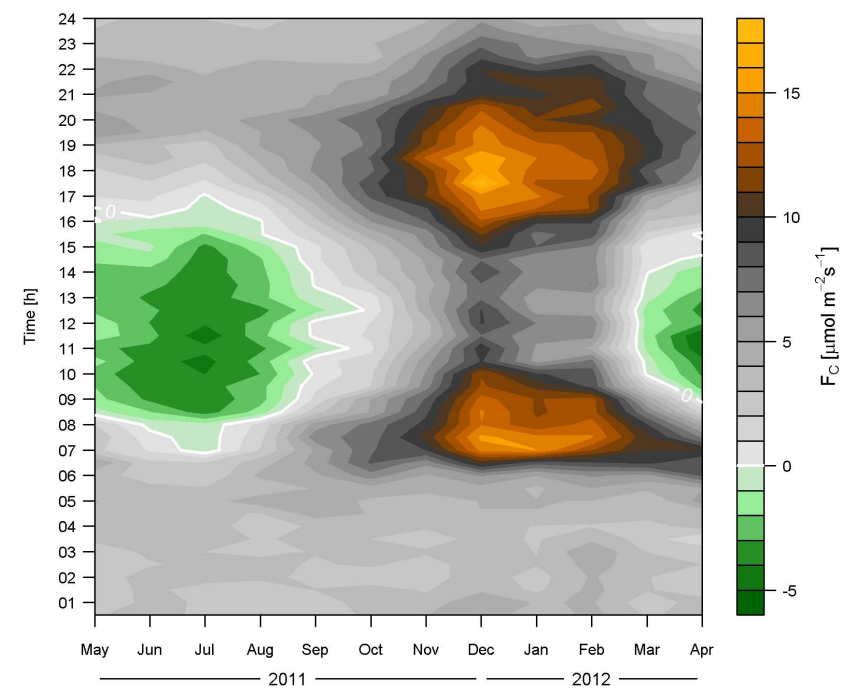

Fig. 12. Temporal variation of monthly ensemble mean carbon fluxes by time of day.

likely heavier traffic load closer to the measurement site (the crossroads to the southwest of the mast is probably the busiest junction within the study area). The Swindon data also show a weaker response to increasing PAR.

The Swindon site is a net source of carbon dioxide in all seasons despite uptake during daytime in the summer. The mean daily carbon release ranges from $0.56 \mathrm{~g} \mathrm{C} \mathrm{m}^{-2} \mathrm{day}^{-1}$ in July to $9.5 \mathrm{~g} \mathrm{C} \mathrm{m}^{-2} \mathrm{day}^{-1}$ in December (averages of monthly mean diurnal cycles). The vegetative draw-down is not large enough to compensate for the emissions on a daily basis but does go some way to offsetting the human impact.

Photosynthetic activity begins early in the year, with the diurnal cycle exhibiting midday uptake in March (Fig. 12). The proportion of evergreen trees around the measurement tower is small, so this is most likely due to grass growth in early spring, occurring before leaf-out of deciduous trees (Peters et al., 2011). Warmer temperatures in the urban environment can also encourage early onset of the growing season compared to rural areas (Zhang et al., 2004). These factors give urban vegetation an advantage in its effectiveness at helping to offset carbon emissions compared to agriculture, for example, where crops may be sown later in the year and harvested early, leaving bare soil for many weeks whilst the urban vegetation continues to photosynthesise, providing there is adequate water available.

From late summer and through autumn, the $\mathrm{CO}_{2}$ fluxes are larger at all times of day, except early morning hours when the flux remains fairly constant across the seasons at around $3 \mu \mathrm{mol} \mathrm{m} \mathrm{m}^{-2} \mathrm{~s}^{-1}$. Anthropogenic activity is minimal for these nighttime hours, photosynthesis nil, and the observed fluxes can be attributed to respiration (soil, plant and human) with a probable slight contribution from emissions due to heating, industrial activities and occasional traffic. A small increase in nighttime $\mathrm{CO}_{2}$ emissions is seen during December and

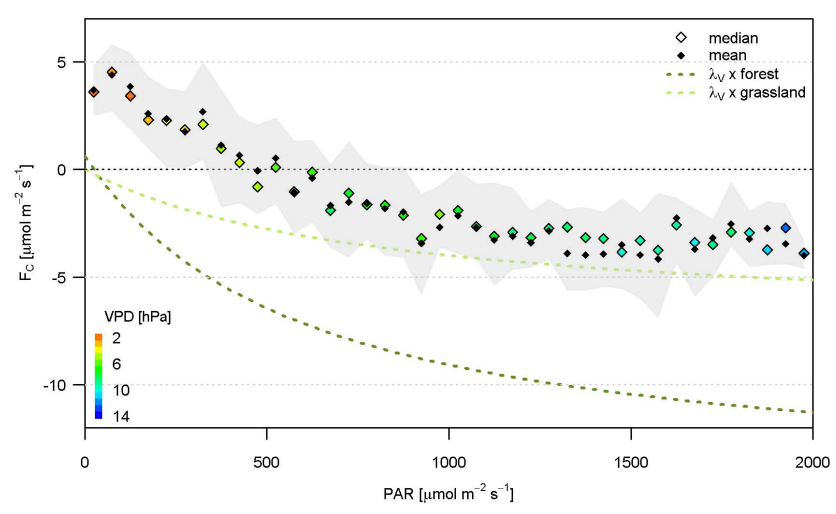

Fig. 13. Summer (JJA) daytime $\left(K_{\downarrow}>5 \mathrm{~W} \mathrm{~m}^{-2}\right)$ carbon flux as a function of photosynthetically active radiation (PAR, in bins of $50 \mu \mathrm{mol} \mathrm{m} \mathrm{m}^{-2} \mathrm{~s}^{-1}$ ). Shaded area is the interquartile range; median values coloured by median vapour pressure deficit (VPD); the models of Schmid et al. (2000) for a mixed deciduous forest ecosystem and Flanagan et al. (2002) for temperate grassland, scaled by the vegetation fraction for Swindon, are shown.

February; these are likely from central heating. February was the coldest month with a mean temperature of $4.2^{\circ} \mathrm{C}$ and two snowy periods (5 February and 10-12 February). Other suburban studies have shown similar patterns (Coutts et al., 2007a), in contrast to more heavily urbanised sites where winter time fluxes are considerably higher than in summer for all hours of the day and throughout the night (Liu et al., 2012; Song and Wang, 2012). This is generally a result of heating a greater density of buildings and heavier traffic loads, and may also be due to some $24 \mathrm{~h}$ industrial contributions.

The rise in carbon emissions from summer to winter illustrates the increasing seasonal impact of anthropogenic activity. Coupled with vegetation being largely dormant during winter, a shift is seen in the drivers of the diurnal $F_{\mathrm{C}}$ cycle. The main controls change from photosynthetic uptake - related to PAR, vegetation fraction and water availability, to human behaviour - the demand for building heating and traffic signals that are no longer masked by uptake (Fig. 12).

To quantitatively examine the impact of anthropogenic activities, the release of $\mathrm{CO}_{2}$ from the combustion of fossil fuels for heating or transport and from human exhalation is estimated following a similar method to $Q_{\mathrm{F}}$ (Appendix A). The emissions from transport are a major source and a direct human impact on the atmosphere (Fig. 14). Two prominent peaks are visible for the winter months and, although strongest in winter, elevated $\mathrm{CO}_{2}$ fluxes can be identified in August during these morning and evening peaks of activity (Fig. 12). As with $Q_{\mathrm{F}}$ these correspond to the daily pattern of human behaviour in residential areas, i.e. rush-hour periods, when roads are busiest, times of building and hot water heating demand (combustion of fossil fuels) and maximal metabolic release from respiration when residents 

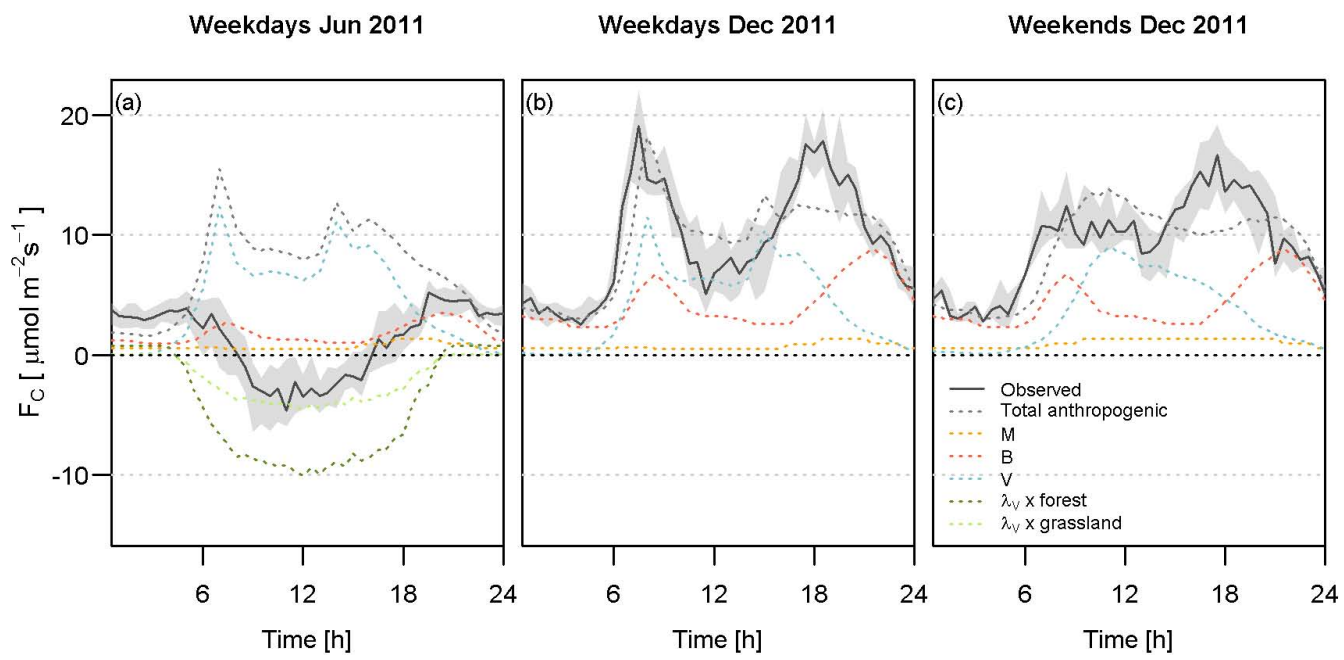

Fig. 14. Diurnal cycle of measured (median: solid lines, interquartile range: shaded) and modelled anthropogenic (mean: dashed lines) carbon fluxes, including components from human metabolism (M), gas usage in buildings (B) and vehicle emissions (V). Uptake by vegetation is modelled for a mixed deciduous forest (Schmid et al., 2000) and temperate grassland (Flanagan et al., 2002) ecosystem scaled by the vegetation fraction for Swindon (a). Weekdays are shown for June 2011 (a) and weekdays and weekends for December 2011 (b, c).

are at home before and after work. With the addition of increased emissions from building heating in winter, these anthropogenic peaks in the diurnal cycle are considerable ( $>10 \mu \mathrm{mol} \mathrm{m}^{-2} \mathrm{~s}^{-1}$ for 5 months of the year). Consistent with other studies, the morning peak is sharpest, with the widely spread evening peak reflecting the end of the school day, variable length of workdays and contributions from heating and cooking which occur throughout the evening. The peak morning flux is also likely enhanced as $\mathrm{CO}_{2}$ stored overnight is flushed out by growth of the boundary layer (Coutts et al., 2007a). At night the shallower boundary layer restricts the dispersion of $\mathrm{CO}_{2}$, causing an increase in concentration. In the morning, as the boundary layer grows again with the increase in vertical mixing, an enhanced flux may be observed as $\mathrm{CO}_{2}$ is transported away from the surface (Reid and Steyn, 1997).

In winter the morning and evening peaks are considerably larger on weekdays compared to weekends, when home heating (and probably leisure travel) contributes to larger positive fluxes during the middle of the day (Fig. 14b, c). Summertime $F_{\mathrm{C}}$ is slightly more positive on weekdays compared to weekends, which is most noticeable during the morning (not shown). Differences between weekday and weekend human behaviour are incorporated into the model and agreement with observed fluxes is best on winter weekdays, but for both types of day the midday modelled fluxes are larger than the observations. This may be the small uptake by evergreen vegetation and grass that is unaccounted for, or more likely a misrepresentation of daily patterns in traffic or building emissions. An overestimated traffic contribution seems likely, especially in the middle of the day, as when compared with estimates from the
National Atmospheric Emissions Inventory ${ }^{2}$ (NAEI), our values for vehicle emissions are larger (approximately double). However, our values for the whole of Swindon match NAEI estimates more closely (10\% underestimation), indicating our assumption of equal traffic distribution over all roads within the Borough of Swindon is a weakness. Human respiration is only really a significant contribution at night (alongside soil and plant respiration). Nighttime measured $F_{\mathrm{C}}$ is larger than the anthropogenic estimates in summer but about the same in winter (Fig. 14), which could be attributed to increased soil and plant respiration with warmer temperatures.

\subsection{Influence of surface cover on fluxes}

The highest vegetation fraction is found to the north of the mast, particularly directly northeast where there are mature trees and lush gardens (Fig. 1). In contrast, the busy road, higher built fraction and increased impervious surfaces lie to the southwest (Fig. 2). The sector $210-240^{\circ}$ has the greatest difference between anthropogenic $(0.60)$ and natural surface cover $\left(\lambda_{V}\right.$ is 0.35$)$. When analysed by wind direction, summer daytime $F_{\mathrm{C}}$ is negative except for the most-built-up sectors: the $0-90^{\circ}$ sector with large lush gardens, quieter roads and a nature reserve beyond shows strong uptake (Fig. 15a). Similarly, when the daytime latent heat flux is normalised by downwelling radiation $\left(Q_{\downarrow}=K_{\downarrow}+L_{\downarrow}\right)$ a greater proportion of the incoming radiation is used in evaporation (just above $10 \%$ ) for the most-vegetated sectors $\left(\lambda_{V} \geq 0.45\right)$ and slightly less for the least-vegetated sectors $\left(\lambda_{V}=0.35-0.40\right.$, about 6-8\%) (Fig. 16a).

\footnotetext{
${ }^{2}$ http://naei.defra.gov.uk
} 


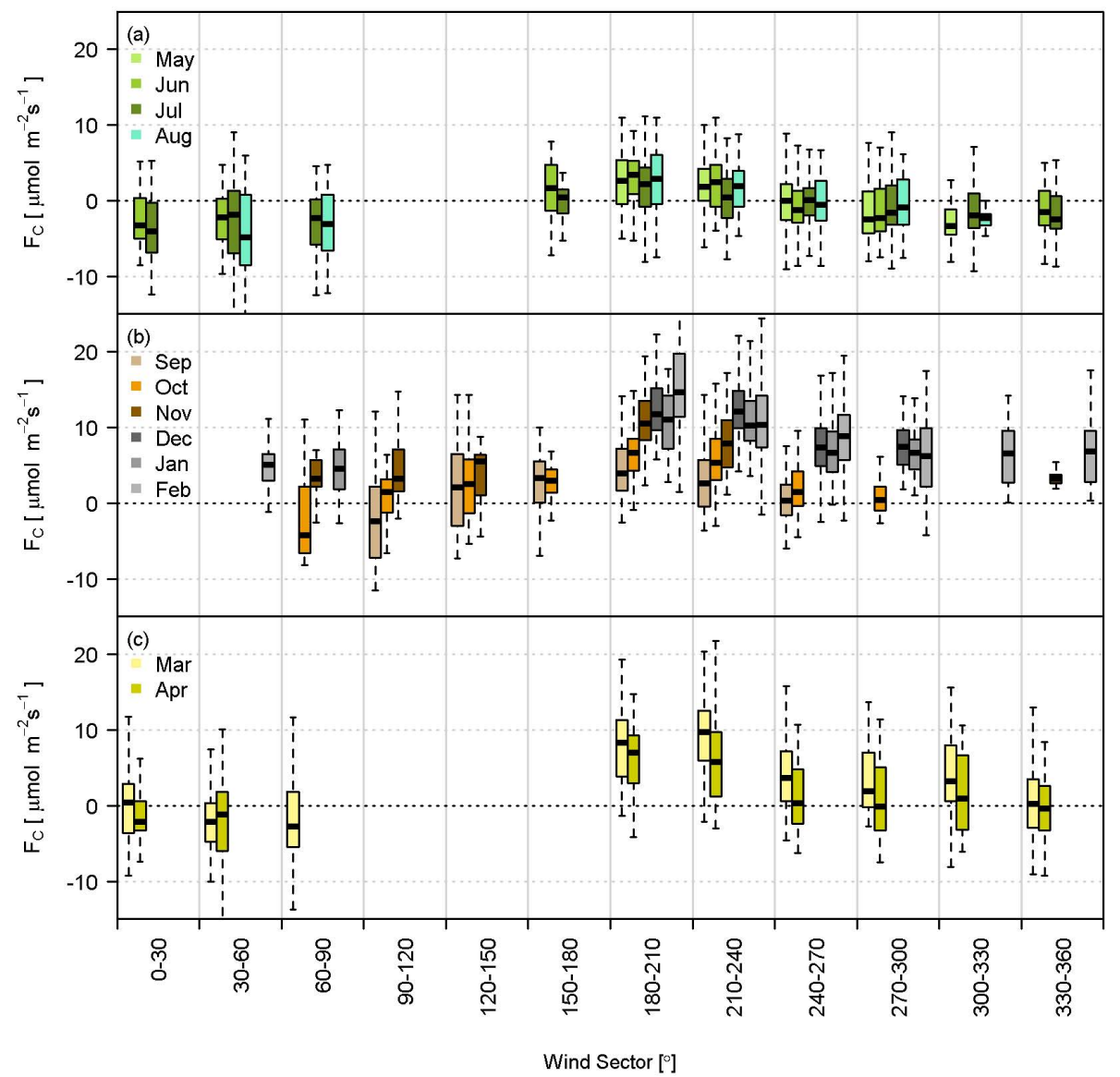

Fig. 15. Monthly boxplots of daytime $\left(K_{\downarrow}>5 \mathrm{~W} \mathrm{~m}^{-2}\right)$ carbon fluxes by wind direction for (a) summer, (b) autumn-winter and (c) spring. Boxes have a minimum of 20 samples.

In autumn, with reduced photosynthesis and increased anthropogenic emissions (Sect. 5.3), $F_{\mathrm{C}}$ increases across all wind sectors (Fig. 15b). The largest wintertime $F_{\mathrm{C}}$ release is from the sectors with the greatest proportion of buildings $\left(180-240^{\circ}\right)$. Trends in the latent heat flux are less clear, but as the incoming radiation diminishes much is returned as outgoing radiation and a smaller fraction of $Q_{\downarrow}$ is converted to turbulent or storage fluxes during winter (Loridan and Grimmond, 2012). In autumn there is still quite high $Q_{\mathrm{E}} / Q_{\downarrow}$ for the $90-180^{\circ}$ sector, and also low $F_{\mathrm{C}}$, which could be due to photosynthesis more likely from grass than deciduous trees (Peters et al., 2011) and evaporation from wet surfaces or moist soils.

In spring (Figs. 15c and 16c), spatial patterns similar to the summer emerge as plants become active again. Anthropogenic $\mathrm{CO}_{2}$ emissions reduce as temperatures increase and daytime average $F_{\mathrm{C}}$ is negative for the more vegetated sectors as photosynthetic uptake begins (March and April, 0-90 ${ }^{\circ}$ ) and transpiration contributes to the total suburban evaporation. As leaves emerge during March-April, these trends of falling $F_{\mathrm{C}}$ and rising $Q_{\mathrm{E}} / Q_{\downarrow}$ are seen fairly consistently across all wind sectors, which reflects the significant proportion of vegetation in the study area as a whole.

Previous studies have demonstrated clear links between surface cover and flux partitioning (Grimmond and Oke, 2002; Christen and Vogt, 2004; Offerle et al., 2006; Goldbach and Kuttler, 2013). For the analysis presented here, no detailed footprint model has been applied; nevertheless, categorising the data by wind sector broadly supports these results. In heterogeneous environments it is important to consider the EC measurement bias introduced by the wind direction distribution during the study period. For example, in Helsinki variable wind direction explains a $16 \%$ difference between annual carbon budgets due to source area characteristics (Järvi et al., 2012).

In Swindon the predominant wind direction is from the southwest (Fig. 3e); therefore, the dataset is expected to be biased towards high $\mathrm{CO}_{2}$ fluxes, relative to the study area as a whole. Some months have few data from particular wind directions (e.g. $0-90^{\circ}$ in May and December). From the observations, Swindon is an annual source of $\mathrm{CO}_{2}$, with a net release of $1.6 \mathrm{~kg} \mathrm{C} \mathrm{m}^{-2} \mathrm{yr}^{-1}$. By considering monthly mean diurnal cycles for different wind sectors, the annual 


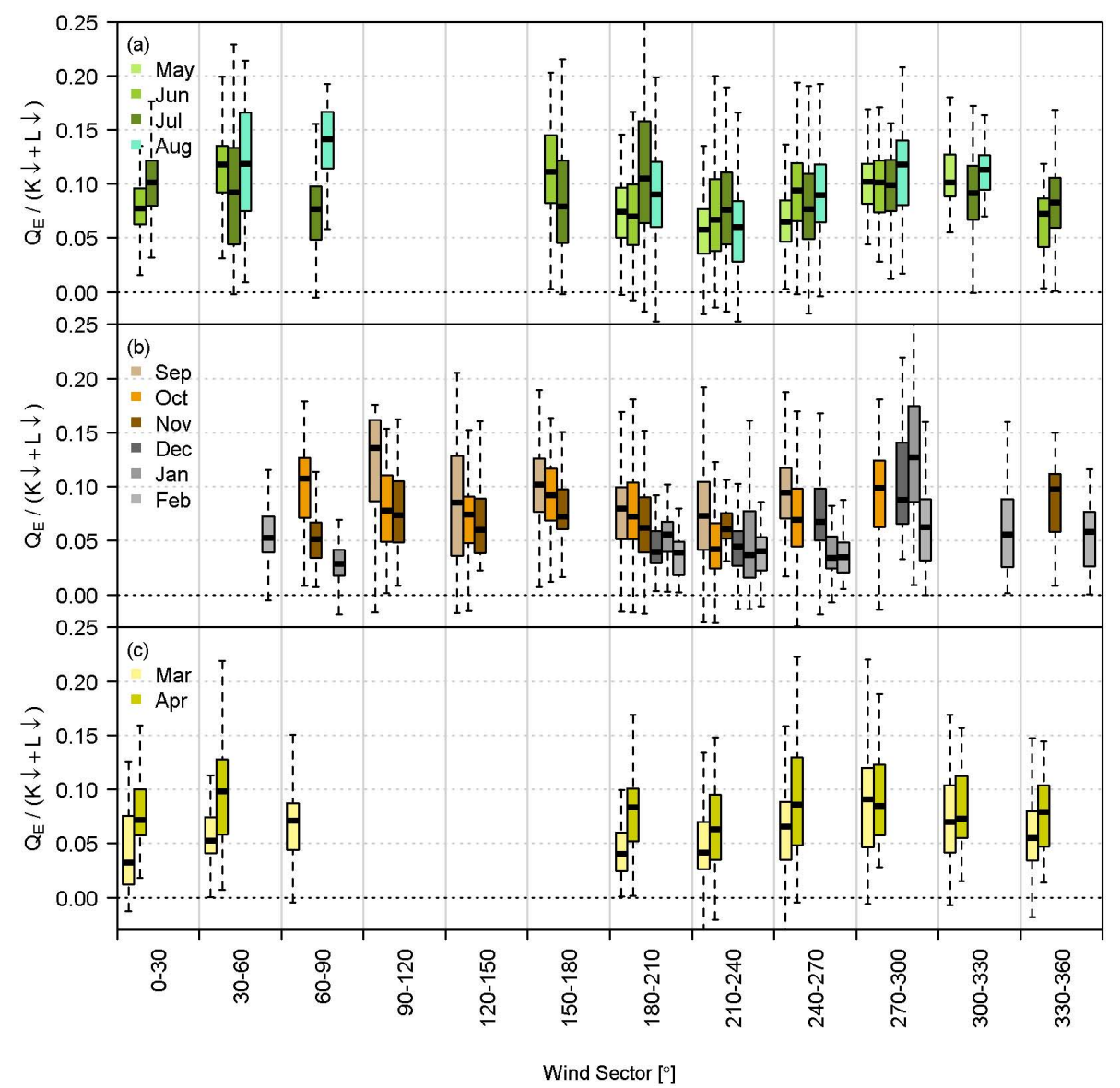

Fig. 16. As for Fig. 15 but for $Q_{\mathrm{E}}$ normalised by incoming radiation.

flux from the least vegetated quadrant with the busiest roads $\left(180-270^{\circ}\right)$ is estimated at $2.0 \mathrm{~kg} \mathrm{C} \mathrm{m}^{-2} \mathrm{yr}^{-1}$, compared to $1.4 \mathrm{~kg} \mathrm{C} \mathrm{m}^{-2} \mathrm{yr}^{-1}$ for the $270-360^{\circ}$ quadrant. These values are considerably lower than other UK studies: both London and Edinburgh emit around $10 \mathrm{~kg} \mathrm{C} \mathrm{m}^{-2} \mathrm{yr}^{-1}$ (Nemitz et al., 2002; Helfter et al., 2011), but comparable to other suburban studies worldwide, such as in Melbourne (Coutts et al., 2007a), Helsinki (Järvi et al., 2012) and Montreal (Bergeron and Strachan, 2011) where emissions are 2.32, 1.76 and $1.36 \mathrm{~kg} \mathrm{C} \mathrm{m}^{-2} \mathrm{yr}^{-1}$, respectively.

In the same way, the total evaporation measured by the EC system will be affected by the wind direction distribution since vegetated areas promote evaporation through transpiration, access to deep water reserves and evaporation from soil, whilst impermeable surfaces can have very high evaporation rates for a short time immediately following rainfall. These large latent heat fluxes immediately after rain (as well as evaporation of intercepted rainfall over all surface types) are usually not captured by the IRGA; therefore, the annual evaporation is likely to be an underestimate. From the measurements, annual evaporation is estimated to be $370 \mathrm{~mm}$, compared to $650 \mathrm{~mm}$ of rainfall for the 12 months May 2011-April 2012.

\section{Conclusions}

The first UK suburban measurements of energy, water and carbon fluxes are presented for a residential area in the town of Swindon for 12 months. The eddy covariance and meteorological data give comparable results to studies in similar environments: the storage flux is a major component of the energy balance all year round, the anthropogenic heat flux is small but important when $Q^{*}$ is small, and more energy is directed into $Q_{\mathrm{H}}$ than $Q_{\mathrm{E}}$ during summer (Fig. 4). In winter there are negative $Q_{\mathrm{H}}$ values (Fig. 5) that can be explained by the suburban nature of the site with relatively low building density, small $Q_{\mathrm{F}}$ and relatively small $\Delta Q_{\mathrm{S}}$ terms compared to sites that are more built-up - and more frequently studied.

A specific aim of this work was to identify the controls on evaporation within the suburban environment. Results show that the latent heat flux remains positive all year round, so under limited radiative input, energy is diverted to evaporation at the expense of $Q_{\mathrm{H}}$. This results in an annual cycle of the Bowen ratio that reaches a minimum of close to zero in December (Fig. 7a). At this time daily (24h) $Q_{\mathrm{H}}$ and $Q_{\mathrm{E}}$ have opposite signs (Fig. 4). Negative $Q_{\mathrm{H}}$ is 
also observed during summer daytimes shortly after rainfall, when evaporation can exceed potential rates. Nighttime $\beta$ exhibits a similar seasonal trend but is lower. At the other extreme, high values of $\beta(>4)$ are seen in both spring 2011 and 2012, when water is scarce (Fig. 7). Significant deviations from the typical $\beta$ of 1-1.5 expected given the vegetation fraction occur outside of summer and on daily timescales in response to water availability (Sect. 5.2).

To further investigate controls on evaporation, surface conductances were calculated using measured variables by season and by time since rainfall. These empirically derived conductances may be useful for assessing or improving model values, e.g. to capture variability in time and across different surface conditions. The diurnal cycle of the observed $g_{\mathrm{s}}$ is asymmetrical, particularly outside of winter, being usually highest in the morning and declining through the afternoon until close to zero at night (Fig. 9). This pattern results from the combined course of $Q_{\mathrm{E}} / \mathrm{VPD}$ over the day. An early morning peak is seen as dew evaporates, and the times of dewfall itself are represented by negative values of $g_{\mathrm{S}}$ as $Q_{\mathrm{E}}$ is directed towards the surface (Fig. 10). Nocturnal $g_{\mathrm{S}}$ is larger when water is abundant and wind speeds are high. Generally, $g_{\mathrm{s}}$ follows a smooth diurnal course; however, when the surface is wet, values are larger and more erratic (Fig. 11). After several days without rain, impervious surface materials limit evaporation compared to the pervious and vegetated areas. Hence, the energy partitioning is strongly dependent on land cover fractions (Sect. 5.4). The active vegetation index proposed by Loridan and Grimmond (2012) to characterise urban surfaces in terms of energy exchange accounts for some seasonal variability through changing leaf area (as opposed to a fixed vegetation fraction), but does not currently parameterise water availability. However, the results presented here suggest linking water availability to surface cover and state of vegetation could offer improved accuracy for modelling the energy partitioning.

Analysis by wind direction reveals the significance of vegetation and traffic on carbon emissions. The annual net carbon release for residential Swindon $\left(1.6 \mathrm{~kg} \mathrm{C} \mathrm{m}^{-2} \mathrm{yr}^{-1}\right)$ is consistent with other studies of similar source area characteristics and is considerably lower than other UK city-based observations. In Swindon, vegetation clearly helps to offset emissions, aided by extended growing seasons (Fig. 12). Vehicle emissions and photosynthetic activity are responsible for the difference between overall daytime uptake and release for different wind sectors around the flux mast. However, even in summer when the diurnal trend is dominated by photosynthesis, daily fluxes $(24 \mathrm{~h})$ indicate $\mathrm{CO}_{2}$ release. Comparison of the modelled anthropogenic $\mathrm{CO}_{2}$ release with the measured fluxes demonstrates the impact of human activities. In December, when vegetation is dormant, the combination of traffic peaks and building emissions match the observed fluxes fairly well (Fig. 14).

Key questions remain if we are to better understand the complex urban environment. Future work should focus particularly on lesser studied conditions - winter months and nighttimes - demanding multi-seasonal observations such as the Swindon dataset presented here. From the analysis discussed above, the change in response of surface fluxes to moisture availability and seasonal controls, as well as to the variability in land cover characteristics, warrants further research.

\section{Appendix A}

\section{Estimating the direct anthropogenic contributions of energy, water and carbon}

The energy balance of urban environments can include a non-negligible addition of energy as a direct result of anthropogenic activities such as building or water heating, electricity use, transport and human metabolism. The heat released during these activities boosts the energy available (from solar input) for turbulent fluxes or storage. In addition to heat release, combustion processes and human respiration produce carbon dioxide and water vapour; hence, the carbon and water cycles also have direct anthropogenic inputs which are not found in natural environments. The additional energy supplied via human activities is represented in the energy balance by $Q_{\mathrm{F}}$, the anthropogenic heat flux, consisting of contributions from vehicular transport $\left(Q_{\mathrm{V}}\right)$, the energy used in buildings $\left(Q_{\mathrm{B}}\right)$ and human metabolism $\left(Q_{\mathrm{M}}\right)$ (Sailor and $\mathrm{Lu}, 2004)$ :

$Q_{\mathrm{F}}=Q_{\mathrm{V}}+Q_{\mathrm{B}}+Q_{\mathrm{M}}$.

The aim here is a first-order estimate to gauge the probable magnitude of these terms for Swindon using UK national statistics available at a range of spatial and temporal resolutions. Sub-daily and monthly variations are of interest for comparison with multi-seasonal eddy covariance observations. At the spatial scale and coarseness of our $Q_{\text {F }}$ estimation, it did not make sense to attempt to calculate differences with land cover (e.g. building density, percentage of road) for different wind sectors around the flux mast. However, it should be kept in mind that, to a certain extent, the EC fluxes will reflect the variable source area measured. Daylight saving was accounted for in the following calculations.

\section{A1 Vehicular emissions}

The total distance travelled by motor vehicles for each local authority in the UK (Department for Transport ${ }^{3}$, (DfT)) was weighted by the area of road in the study area, assuming the weight of traffic is equal across all roads as in Ichinose et al. (1999). This resulted in 122 million vehicle $\mathrm{km} \mathrm{yr}^{-1}$, which when divided by the representative area and converted

\footnotetext{
${ }^{3}$ http://www.dft.gov.uk/statistics/series/traffic
} 
from years to seconds gives the average vehicle $\mathrm{km}$ per unit area per second. Multiplying by emission factors for the amount of energy, $\mathrm{CO}_{2}$ and water vapour released per $\mathrm{km}$ travelled yielded $Q_{\mathrm{V}}$, the contribution of traffic to $F_{\mathrm{C}}$ and the anthropogenic water vapour flux from traffic. Emission factors from the Department of Energy and Climate Change ${ }^{4}$, (DECC) and Moriwaki and Kanda (2004) of $0.2069 \mathrm{~kg} \mathrm{~km}^{-1}$ and $0.0990 \mathrm{~kg} \mathrm{~km}^{-1}$, with a mean fuel economy of $8.5 \mathrm{~km}$ $\mathrm{L}^{-1}$ (Sailor and $\mathrm{Lu}, 2004$ ), were used for $\mathrm{CO}_{2}$ and $\mathrm{H}_{2} \mathrm{O}$, respectively. For $Q_{\mathrm{V}}$ a mean energy release of $3.97 \mathrm{MJ} \mathrm{km}^{-1}$ from Sailor and Lu (2004) has been used. No adjustment for fleet composition or variable fuel economy was made as no data specific to Swindon were available. Temporal changes were modelled using typical daily (Monday-Friday, Saturday, Sunday) and monthly profiles from the National Travel Survey 2010 ${ }^{5}$, (DfT).

\section{A2 Building energy use}

To estimate the outputs of energy use in buildings the following assumptions were made:

1. All energy released from fuel consumption or electricity use in buildings is eventually dissipated as heat.

2. No allowance is made for time lags between energy consumption and release to the surroundings.

3. Only domestic energy use is considered as residential areas are judged to be the predominant land use. There are a few institutional buildings (mainly schools) and small supermarkets plus a row of shops to the southwest (Fig. 1). Domestic energy use data are probably an underestimate and may misrepresent the daily and seasonal patterns (non-domestic energy use typically remains high throughout the workday and decreases in the evening, see Hamilton et al. (2009), and shows less variation across seasons) - but the prevalence of residential buildings means the likely impact is small.

4. Whilst the dissipation of heat from electricity used in the home but generated at out of town power plants will result in additional heating that contributes to the observations, the emissions from these power plants do not contribute to $\mathrm{CO}_{2}$ measured at the flux tower.

Annual domestic electricity and gas consumption statistics were available up to 2009 for different areas within Swindon, whilst consumption in 2011-2012 was available quarterly for gas and monthly for electricity for the UK (DECC). The latter provides more information on temporal changes which can be determined, for example, by the weather (mild winter in 2011) and cost of fuel. In 2009, approximately

\footnotetext{
${ }^{4}$ http://www.decc.gov.uk

${ }^{5}$ http://www.dft.gov.uk/statistics/releases/ national-travel-survey-2010
}

$0.3 \%$ of the UK's total electricity and gas use was consumed by Swindon Borough, of which about $85 \%$ was used by Swindon Town. These proportions are assumed to remain similar for 2011-2012 to obtain quarterly and monthly energy use. $\mathrm{CO}_{2}$ and water vapour release were estimated based on consumption of natural gas (Moriwaki and Kanda, 2004). Other energy sources (e.g. burning of biomass, coal, oil) were neglected. The sub-daily variation was modelled using Hamilton et al. (2009), linearly interpolated to $30 \mathrm{~min}$ profiles.

\section{A3 Human metabolism}

Nighttime and daytime population densities from the 2001 census were used to estimate heat and gas emissions from human metabolism. For the study area the population has not changed significantly $(-1.5 \%)$ between 2001 and 2010 (Office for National Statistics ${ }^{6}$ ), although the population of Swindon Town has grown significantly $(+14 \%)$ as development has rapidly progressed to the north and west. Following Bergeron and Strachan (2010), nighttime population densities were used for weekday nighttimes (18:00-06:00), weekends and holidays; lower daytime population densities were used for weekdays when residents would be at work (08:00-16:00); and linear interpolation filled the transition times. The daytime (175 $\mathrm{W}_{\text {person }}{ }^{-1}, \quad 08: 00-21: 00$ on weekdays, 09:00-21:00 on weekends/holidays), nighttime (75 $\mathrm{W}_{\text {person }}{ }^{-1}$, 23:00-06:00 on weekdays, 23:00-07:00 on weekends/holidays) and transition period ( $125 \mathrm{~W}_{\text {person }}{ }^{-1}$, between times) heat released depending on activity is based on Sailor and $\mathrm{Lu}$ (2004). Figures for $\mathrm{CO}_{2}$ and water vapour release are adjusted for day, night and transition times (280, 120 and $200 \mu \mathrm{mol} \mathrm{CO}_{2} \mathrm{~s}^{-1}$ person $^{-1} ; 31.5,13.5$ and $22.5 \mathrm{~W}$ person $^{-1}$ ) based on Moriwaki and Kanda (2004). Combining the population densities with the per capita emissions yielded fluxes of anthropogenic heat, $\mathrm{CO}_{2}$ and latent heat due to human metabolism.

These estimates do not account for details such as residents on holiday, night shifts, more or less active lifestyles, or people travelling into the area for education, to work or shop. However, many of these contributing factors tend to compensate. The methodology could be refined by more intensive data collection and increased complexity of models, as has been trialled in other studies: Nemitz et al. (2002) obtained hourly gas supply data for Edinburgh; detailed traffic monitoring was available in London (Helfter et al., 2011). For suburban areas an order of magnitude figure may be sufficient to demonstrate that $Q_{\mathrm{F}}$ is a relatively small contribution to the overall energy balance; improving the accuracy of $\mathrm{CO}_{2}$ emission estimates might be more relevant. The water vapour released through anthopogenic activities was found to be a negligible component of the total $Q_{\mathrm{E}}$ as

\footnotetext{
${ }^{6}$ http://www.statistics.gov.uk/hub/population
} 
shown in other studies (Moriwaki and Kanda, 2004), except near cooling towers (Moriwaki et al., 2008).

\section{Appendix B}

\section{Net storage heat flux estimation}

The net storage heat flux, a significant term in the urban energy balance, is difficult to measure directly. As shown in Fig. 4, the residual term can be very large and was judged a poor estimate of the likely storage flux for this dataset. Several heat flux plates were installed within different materials in Swindon (under soil, vegetation and rubble, between a roof and roof lining) to give a qualitative indication of the different behaviour between the multiple material types that make up the urban fabric. The practicalities of obtaining sufficient spatial representation and the assumptions required to use such measurements to determine a representative storage term demand a different approach. To avoid these issues we estimate the storage heat flux using the objective hysteresis model (OHM) of Grimmond et al. (1991). The method uses Camuffo and Bernardi's (1982) hysteresis regression approach with net all-wave radiation and a rate-of-change term for the hysteresis between $Q^{*}$ and $\Delta Q_{\mathrm{S}}$. The coefficients are applied objectively based on the different land cover types weighted by their relative proportions of the surface. Thus, the storage flux is estimated from (Grimmond et al., 1991)

$\Delta Q_{\mathrm{S}}=\sum_{i}\left\{a_{1 i} Q^{*}+a_{2 i}\left(\partial Q^{*} / \partial t\right)+a_{3 i}\right\} f_{i}$,

where $t$ is time and $a_{1,2,3}$ are coefficients for each land cover type, $i$, covering an area fraction $f_{i}$. For Swindon the plan area fractions (Table 1) were used. Coefficients used were taken from Table 1 of Grimmond et al. (1991), using an average of the values given for each land cover type, asphalt for roads and bare soil for surfaces classified as "Other". The resulting coefficients obtained for Swindon $\left(a_{1}=0.39\right.$, $\left.a_{2}=0.35, a_{3}=-27.0\right)$ are comparable to those at Sunset, Vancouver.

These coefficients were used all year round. Anandakumar (1999) derived a set of coefficients for asphalt which revealed seasonal variation, notably the large negative values of $a_{3}$ found during summer became smaller and even positive during winter. For the Swindon data, fitting Eq. (B1) to the soil heat flux $Q_{\mathrm{G}}$ suggested similar seasonal variation of the coefficients, particularly $a_{3}$. Clearly, this topic warrants further research. A further limitation is that the proportion of incoming energy dissipated by conduction can vary when surfaces are wet compared to dry (Offerle et al., 2005b; Kawai and Kanda, 2010). Ideally, the estimation of $\Delta Q_{\mathrm{S}}$ would incorporate changing seasonal and surface conditions, but the variety of surface types and lack of long-term datasets means this is beyond the scope of the present study.
Acknowledgements. We wish to thank the owners of the Swindon property who very kindly agreed to have the flux mast installed in their garden. We appreciate the constructive comments of both anonymous reviewers. This work was funded by the Natural Environment Research Council, UK.

Edited by: J. Rinne

\section{References}

Allen, L., Lindberg, F., and Grimmond, C. S. B.: Global to city scale urban anthropogenic heat flux: Model and variability, Int J. Climatol., 31, 1990-2005, doi:10.1002/joc.2210, 2011.

Anandakumar, K.: A study on the partition of net radiation into heat fluxes on a dry asphalt surface, Atmos. Environ., 33, 3911-3918, 1999.

Arnfield, A. J.: Two decades of urban climate research: A review of turbulence, exchanges of energy and water, and the urban heat island, Int. J. Climatol., 23, 1-26, doi:10.1002/joc.859, 2003.

Balogun, A., Adegoke, J., Vezhapparambu, S., Mauder, M., McFadden, J., and Gallo, K.: Surface energy balance measurements above an exurban residential neighbourhood of Kansas City, Missouri, Bound.-Layer Meteorol., 133, 299-321, doi:10.1007/s10546-009-9421-3, 2009.

Balogun, A., Tomlin, A., Wood, C., Barlow, J., Belcher, S., Smalley, R., Lingard, J., Arnold, S., Dobre, A., Robins, A., Martin, D., and Shallcross, D.: In-street wind direction variability in the vicinity of a busy intersection in central London, Bound.-Layer Meteorol., 136, 489-513, doi:10.1007/s10546-010-9515-y, 2010.

Bergeron, O. and Strachan, I. B.: Wintertime radiation and energy budget along an urbanization gradient in Montreal, Canada, Int. J. Climatol., 32, 137-152, doi:10.1002/joc.2246, 2010.

Bergeron, O. and Strachan, I. B.: $\mathrm{CO}_{2}$ sources and sinks in urban and suburban areas of a northern mid-latitude city, Atmos. Environ., 45, 1564-1573, 2011.

Best, M. J. and Grimmond, C. S. B.: Analysis of the seasonal cycle within the first international urban land-surface model comparison, Bound. Layer Meteorol., 146, 421-446, doi:10.1007/s10546-012-9769-7, 2013.

Blonquist Jr., J. M., Tanner, B. D., and Bugbee, B.: Evaluation of measurement accuracy and comparison of two new and three traditional net radiometers, Agric. For. Meteorol., 149, 1709-1721, doi:10.1016/j.agrformet.2009.05.015, 2009.

Brutsaert, W.: Evaporation into the atmosphere: Theory, history, and applications, Kluwer Academic Publishers, 299 pp., 1982.

Camuffo, D. and Bernardi, A.: An observational study of heat fluxes and their relationships with net radiation, Bound.-Layer Meteorol., 23, 359-368, doi:10.1007/bf00121121, 1982.

Christen, A. and Vogt, R.: Energy and radiation balance of a central European city, Int. J. Climatol., 24, 1395-1421, doi:10.1002/joc.1074, 2004.

Collier, C. G.: The impact of urban areas on weather, Q. J. Roy Meteorol. Soc., 132, 1-25, doi:10.1256/qj.05.199, 2006.

Coutts, A. M., Beringer, J., and Tapper, N. J.: Characteristics influencing the variability of urban $\mathrm{CO}_{2}$ fluxes in Melbourne, Australia, Atmos. Environ., 41, 51-62, 2007a.

Coutts, A. M., Beringer, J., and Tapper, N. J.: Impact of increasing urban density on local climate: Spatial and temporal variations in the surface energy balance in Melbourne, Australia, J. 
Appl. Meteorol. Climatol., 46, 477-493, doi:10.1175/jam2462.1, $2007 b$.

Crawford, B., Grimmond, C. S. B., and Christen, A.: Five years of carbon dioxide fluxes measurements in a highly vegetated suburban area, Atmos. Environ., 45, 896-905, 2011.

Flanagan, L. B., Wever, L. A., and Carlson, P. J.: Seasonal and interannual variation in carbon dioxide exchange and carbon balance in a northern temperate grassland, Glob. Change Biol., 8, 599-615, doi:10.1046/j.1365-2486.2002.00491.x, 2002.

Foken, T.: The energy balance closure problem: An overview, Ecol. Appl., 18, 1351-1367, 2008.

Foken, T. and Wichura, B.: Tools for quality assessment of surface-based flux measurements, Agric. For. Meteorol., 78, 83-105, doi:10.1016/0168-1923(95)02248-1, 1996.

Fortuniak, K., Pawlak, W., and Siedlecki, M.: Integral turbulence statistics over a central European city centre, Bound.-Layer Meteorol., 146, 257-276, doi:10.1007/s10546-012-9762-1, 2013.

Goldbach, A. and Kuttler, W.: Quantification of turbulent heat fluxes for adaptation strategies within urban planning, Int. J. Climatol., 33, 143-159, doi:10.1002/joc.3437, 2013.

Grimmond, C. S. B.: The suburban energy balance: Methodological considerations and results for a mid-latitude west coast city under winter and spring conditions, Int. J. Climatol., 12, 481-497, doi:10.1002/joc.3370120506, 1992.

Grimmond, C. S. B.: Climate of cities, In: The Routledge handbook of urban ecology, Routledge, 103-119, 2010.

Grimmond, C. S. B. and Oke, T. R.: An evapotranspirationinterception model for urban areas, Water Resour. Res., 27, 1739-1755, 1991.

Grimmond, C. S. B. and Oke, T. R.: Comparison of heat fluxes from summertime observations in the suburbs of four North American cities, J. Appl. Meteorol., 34, 873-889, doi:10.1175/1520-0450, 1995.

Grimmond, C. S. B., and Oke, T. R.: Aerodynamic properties of urban areas derived from analysis of surface form, J. Appl. Meteorol., 38, 1262-1292, 1999a.

Grimmond, C. S. B. and Oke, T. R.: Heat storage in urban areas: Local-scale observations and evaluation of a simple model., J. Appl. Meteorol. Climatol., 38, 922-940, 1999 b.

Grimmond, C. S. B. and Oke, T. R.: Rates of evaporation in urban areas. Impacts of urban growth on surface and ground waters, Int. Assoc. Hydrol. Sci. Publ., 259, 235-243, 1999c.

Grimmond, C. S. B. and Oke, T. R.: Turbulent heat fluxes in urban areas: Observations and a local-scale urban meteorological parameterization scheme (LUMPS), J. Appl. Meteorol., 41, 792-810, 2002.

Grimmond, C. S. B., Cleugh, H. A., and Oke, T. R.: An objective urban heat storage model and its comparison with other schemes, Atmos. Environ. B Urban Atmosphere, 25, 311-326, 1991.

Grimmond, C. S. B., King, T. S., Roth, M., and Oke, T. R.: Aerodynamic roughness of urban areas derived from wind observations, Bound.-Layer Meteorol., 89, 1-24, 1998.

Grimmond, C. S. B., Salmond, J. A., Oke, T. R., Offerle, B., and Lemonsu, A.: Flux and turbulence measurements at a densely built-up site in Marseille: Heat, mass (water and carbon dioxide), and momentum, J. Geophys. Res.-Atmos., 109, D24101, doi:10.1029/2004jd004936, 2004.

Grimmond, C. S. B., Roth, M., Oke, T. R., Au, Y. C., Best, M., Betts, R., Carmichael, G., Cleugh, H., Dabberdt, W., Emmanuel,
R., Freitas, E., Fortuniak, K., Hanna, S., Klein, P., Kalkstein, L. S., Liu, C. H., Nickson, A., Pearlmutter, D., Sailor, D., and Voogt, J.: Climate and more sustainable cities: Climate information for improved planning and management of cities (producers/capabilities perspective), Procedia Environmental Sciences, 1, 247-274, 2010.

Gwilliam, M., Bourne, C., Swain, C., and Pratt, A., Sustainable renewal of suburban areas, Joseph Rowntree Foundation, York, UK, 87 pp., 1998.

Hamilton, I. G., Davies, M., Steadman, P., Stone, A., Ridley, I., and Evans, S.: The significance of the anthropogenic heat emissions of London's buildings: A comparison against captured shortwave solar radiation, Build. Environ., 44, 807-817, 2009.

Heath, M. A., Walshe, J. D., and Watson, S. J.: Estimating the potential yield of small building-mounted wind turbines, Wind Energ., 10, 271-287, doi:10.1002/we.222, 2007.

Helfter, C., Famulari, D., Phillips, G. J., Barlow, J. F., Wood, C. R., Grimmond, C. S. B., and Nemitz, E.: Controls of carbon dioxide concentrations and fluxes above central London, Atmos. Chem. Phys., 11, 1913-1928, doi:10.5194/acp-11-1913-2011, 2011.

Högström, U.: Non-dimensional wind and temperature profiles in the atmospheric surface layer: A re-evaluation, Bound.-Layer Meteorol., 42, 55-78, doi:10.1007/bf00119875, 1988.

Home, R.: Land ownership in the United Kingdom: Trends, preferences and future challenges, Land Use Policy, 26, Supplement 1, S103-S108, 2009.

Hsieh, C. I., Katul, G., and Chi, T.: An approximate analytical model for footprint estimation of scalar fluxes in thermally stratified atmospheric flows, Adv. Water Resour., 23, 765-772, 2000 .

Ichinose, T., Shimodozono, K., and Hanaki, K.: Impact of anthropogenic heat on urban climate in Tokyo, Atmos. Environ., 33, 3897-3909, 1999.

Järvi, L., Grimmond, C. S. B., and Christen, A.: The surface urban energy and water balance scheme (SUEWS): Evaluation in Los Angeles and Vancouver, J. Hydrol., 411, 219-237, 2011.

Järvi, L., Nordbo, A., Junninen, H., Riikonen, A., Moilanen, J., Nikinmaa, E., and Vesala, T.: Seasonal and annual variation of carbon dioxide surface fluxes in Helsinki, Finland, in 2006-2010, Atmos. Chem. Phys., 12, 8475-8489, doi:10.5194/acp-12-84752012, 2012.

Kawai, T. and Kanda, M.: Urban energy balance obtained from the comprehensive outdoor scale model experiment. Part i: Basic features of the surface energy balance, J. Appl. Meteorol. Climatol., 49, 1341-1359, doi:10.1175/2010jamc1992.1, 2010.

Kawai, T., Ridwan, M. K., and Kanda, M.: Evaluation of the simple urban energy balance model using selected data from 1-yr flux observations at two cities, J. Appl. Meteorol. Climatol., 48, 693715, doi:10.1175/2008jamc1891.1, 2009.

Kotthaus, S. and Grimmond, C. S. B.: Identification of micro-scale anthropogenic $\mathrm{CO}_{2}$, heat and moisture sources - processing eddy covariance fluxes for a dense urban environment, Atmos. Environ., 57, 301-316, 2012.

Leuning, R., van Gorsel, E., Massman, W. J., and Isaac, P. R.: Reflections on the surface energy imbalance problem, Agric. For. Meteorol., 156, 65-74, 2012.

Lindberg, F. and Grimmond, C.: Nature of vegetation and building morphology characteristics across a city: Influence on shadow patterns and mean radiant temperatures in London, Urban 
Ecosyst., 14, 617-634, doi:10.1007/s11252-011-0184-5, 2011.

Liu, H. Z., Feng, J. W., Järvi, L., and Vesala, T.: Four-year (2006-2009) eddy covariance measurements of $\mathrm{CO}_{2}$ flux over an urban area in Beijing, Atmos. Chem. Phys., 12, 7881-7892, doi:10.5194/acp-12-7881-2012, 2012.

Loridan, T. and Grimmond, C. S. B.: Characterization of energy flux partitioning in urban environments: Links with surface seasonal properties, J. Appl. Meteorol. Climatol., 51, 219-241, doi:10.1175/jamc-d-11-038.1, 2012.

Mauder, M., Liebethal, C., Göckede, M., Leps, J.-P., Beyrich, F., and Foken, T.: Processing and quality control of flux data during LITFASS-2003, Bound.-Layer Meteorol., 121, 67-88, doi:10.1007/s10546-006-9094-0, 2006.

Mayer, H.: Air pollution in cities, Atmos. Environ., 33, 4029-4037, 1999.

Mitchell, V. G., Cleugh, H. A., Grimmond, C. S. B., and Xu, J.: Linking urban water balance and energy balance models to analyse urban design options, Hydrol. Process., 22, 2891-2900, doi:10.1002/hyp.6868, 2008.

Moncrieff, J. B., Massheder, J. M., de Bruin, H., Elbers, J., Friborg, T., Heusinkveld, B., Kabat, P., Scott, S., Soegaard, H., and Verhoef, A.: A system to measure surface fluxes of momentum, sensible heat, water vapour and carbon dioxide, J. Hydrol., 188-199, 589-611, 1997.

Monteith, J. L.: Evaporation and environment, Symposia of the Society for Experimental Biology, 19, 205-224, 1965.

Moriwaki, R. and Kanda, M.: Seasonal and diurnal fluxes of radiation, heat, water vapor, and carbon dioxide over a suburban area, J. Appl. Meteorol., 43, 1700-1710, 2004.

Moriwaki, R., Kanda, M., Senoo, H., Hagishima, A., and Kinouchi, T.: Anthropogenic water vapor emissions in Tokyo, Water Resour. Res., 44, W11424, doi:10.1029/2007wr006624, 2008.

Nemitz, E., Hargreaves, K. J., McDonald, A. G., Dorsey, J. R., and Fowler, D.: Meteorological measurements of the urban heat budget and $\mathrm{CO}_{2}$ emissions on a city scale, Environ. Sci. Technol., 36, 3139-3146, doi:10.1021/es010277e, 2002.

Newton, T., Oke, T. R., Grimmond, C. S. B., and Roth, M.: The suburban energy balance in Miami, Florida, Geografiska Annaler: Series A, Phys. Geogr., 89, 331-347, doi:10.1111/j.1468-0459.2007.00329.x, 2007.

Nordbo, A., Järvi, L., Haapanala, S., Moilanen, J., and Vesala, T.: Intra-city variation in urban morphology and turbulence structure in Helsinki, Finland, Bound.-Layer Meteorol., 146, 469-496, doi:10.1007/s10546-012-9773-y, 2013.

Offerle, B., Grimmond, C. S. B., and Fortuniak, K.: Heat storage and anthropogenic heat flux in relation to the energy balance of a central European city centre, Int. J. Climatol., 25, 1405-1419, doi:10.1002/koc.1198, 2005a.

Offerle, B., Jonsson, P., Eliasson, I., and Grimmond, C. S. B.: Urban modification of the surface energy balance in the West African Sahel: Ouagadougou, Burkina Faso, J. Clim., 18, 3983-3995, doi:10.1175/jcli3520.1, 2005b.

Offerle, B., Grimmond, C. S. B., Fortuniak, K., and Pawlak, W.: Intraurban differences of surface energy fluxes in a central European city, J. Appl. Meteorol. Climatol., 45, 125-136, 2006.

Oke, T. R.: The energetic basis of the urban heat-island, Q. J. Roy. Meteorol. Soc., 108, 1-24, 1982.

Oke, T. R.: Boundary layer climates, Routledge, Taylor and Francis Group, 435 pp., 1987.
Oke, T. R., Spronken-Smith, R. A., Jáuregui, E., and Grimmond, C. S. B.: The energy balance of central Mexico city during the dry season, Atmos. Environ., 33, 3919-3930, 1999.

Papaioannou, G., Papanikolaou, N., and Retalis, D.: Relationships of photosynthetically active radiation and shortwave irradiance, Theor. Appl. Climatol., 48, 23-27, doi:10.1007/bf00864910, 1993.

Pawlak, W., Fortuniak, K., and Siedlecki, M.: Carbon dioxide flux in the centre of Łódź, Poland - analysis of a 2-year eddy covariance measurement data set, Int. J. Climatol., 31, 232-243, doi:10.1002/joc.2247, 2010.

Peters, E. B., Hiller, R. V., and McFadden, J. P.: Seasonal contributions of vegetation types to suburban evapotranspiration, J. Geophys. Res., 116, G01003, doi:10.1029/2010jg001463, 2011.

Priestley, C. H. B., and Taylor, R. J.: On the assessment of surface heat flux and evaporation using large-scale parameters, Mon. Weather Rev., 100, 81-92, doi:10.1175/1520-0493, 1972.

Reid, K. H. and Steyn, D. G.: Diurnal variations of boundary-layer carbon dioxide in a coastal city - observations and comparison with model results, Atmos. Environ., 31, 3101-3114, doi:10.1016/S1352-2310(97)00050-2, 1997.

Roberts, S. M., Oke, T. R., Grimmond, C. S. B., and Voogt, J. A.: Comparison of four methods to estimate urban heat storage, J. Appl. Meteorol. Climatol., 45, 1766-1781, doi:10.1175/jam2432.1, 2006.

Roth, M.: Review of atmospheric turbulence over cities, Q. J. Roy. Meteorol. Soc., 126, 941-990, doi:10.1002/qj.49712656409, 2000.

Sailor, D. J. and Lu, L.: A top-down methodology for developing diurnal and seasonal anthropogenic heating profiles for urban areas, Atmos. Environ., 38, 2737-2748, 2004.

Schmid, H. P., Cleugh, H. A., Grimmond, C. S. B., and Oke, T. R.: Spatial variability of energy fluxes in suburban terrain, Bound.Layer Meteorol., 54, 249-276, doi:10.1007/bf00183956, 1991.

Schmid, H. P., Grimmond, C. S. B., Cropley, F., Offerle, B., and $\mathrm{Su}, \mathrm{H}$.-B.: Measurements of $\mathrm{CO}_{2}$ and energy fluxes over a mixed hardwood forest in the mid-western United States, Agric. For. Meteorol., 103, 357-374, 2000.

Slatyer, R. O. and McIlroy, I. C.: Practical microclimatology, CSIRO, Melbourne, Australia, 310 pp., 1961.

Song, T. and Wang, Y.: Carbon dioxide fluxes from an urban area in Beijing, Atmos. Res., 106, 139-149, 2012.

Thomas, M. V., Malhi, Y., Fenn, K. M., Fisher, J. B., Morecroft, M. D., Lloyd, C. R., Taylor, M. E., and McNeil, D. D.: Carbon dioxide fluxes over an ancient broadleaved deciduous woodland in southern england, Biogeosciences, 8, 1595-1613, doi:10.5194/bg-8-1595-2011, 2011.

van Ulden, A. P. and Holtslag, A. A. M.: Estimation of atmospheric boundary layer parameters for diffusion applications, J. Clim. Appl. Meteorol., 24, 1196-1207, 1985.

Vesala, T., Järvi, L., Launiainen, S., Sogachev, A., Rannik, Ü., Mammarella, I., Siivola, E., Keronen, P., Rinne, J., Riikonen, A. N. U., and Nikinmaa, E.: Surface-atmosphere interactions over complex urban terrain in Helsinki, Finland, Tellus B, 60, 188-199, doi:10.1111/j.1600-0889.2007.00312.x, 2008.

Webb, E. K., Pearman, G. I., and Leuning, R.: Correction of flux measurements for density effects due to heat and water-vapor transfer, Q. J. Roy. Meteorol. Soc., 106, 85-100, 1980. 
Weber, S. and Kordowski, K.: Comparison of atmospheric turbulence characteristics and turbulent fluxes from two urban sites in Essen, Germany, Theor. Appl. Climatol., 102, 61-74, doi:10.1007/s00704-009-0240-8, 2010.

Wilson, K., Goldstein, A., Falge, E., Aubinet, M., Baldocchi, D., Berbigier, P., Bernhofer, C., Ceulemans, R., Dolman, H., Field, C., Grelle, A., Ibrom, A., Law, B. E., Kowalski, A., Meyers, T., Moncrieff, J., Monson, R., Oechel, W., Tenhunen, J., Valentini, R., and Verma, S.: Energy balance closure at FLUXNET sites, Agric. For. Meteorol., 113, 223-243, 2002.
Xie, X. M., Huang, Z., and Wang, J. S.: Impact of building configuration on air quality in street canyon, Atmos. Environ., 39, 4519-4530, doi:10.1016/j.atmosenv.2005.03.043, 2005.

Zhang, X., Friedl, M. A., Schaaf, C. B., Strahler, A. H., and Schneider, A.: The footprint of urban climates on vegetation phenology, Geophys. Res. Lett., 31, L12209, doi:10.1029/2004g1020137, 2004. 